\title{
Overexpression of Dominant Negative Peroxisome Proliferator-Activated Receptor- $\gamma$ (PPAR $\gamma$ ) in Alveolar Type II Epithelial Cells Causes Inflammation and T-Cell Suppression in the Lung
}

\author{
Lingyan Wu, ${ }^{\star \dagger}$ Guixue Wang, ${ }^{*}$ Peng Qu, ${ }^{\neq}$ \\ Cong Yan, ${ }^{\ddagger}$ and Hong $\mathrm{Du}^{\dagger}$ \\ From the Bioengineering College," ChongQing University, \\ ChongQing, China; the Division of Human Genetics, ${ }^{\dagger}$ Cincinnati \\ Children's Hospital Medical Center, Cincinnati, Obio; and the \\ Center for Immunobiology, Department of Pathology and \\ Laboratory Medicine, Indiana University School of Medicine, \\ Indianapolis, Indiana
}

Peroxisome proliferator-activated receptor- $\gamma(\operatorname{PPAR} \gamma)$ is an anti-inflammatory molecule. To assess its biological function in lung alveolar epithelial cells, a CCSP-rtTA/ (tetO) $)_{7}$-dnPPAR $\gamma$ bitransgenic mouse model was generated. In this model, a dominant negative (dn) PPAR $\gamma$ Flag fusion protein was overexpressed in lung alveolar type II (AT II) epithelial cells in an inducible manner to suppress the endogenous PPAR $\gamma$ function. Overexpression of $\operatorname{dnPPAR} \gamma$ induces up-regulation of proinflammatory cytokines and chemokines at both mRNA and protein levels in AT II epithelial cells. This up-regulation was due to dnPPAR $\gamma$ directly DNA binding on the promoter regions. Up-regulation of proinflammatory molecules activated multiple intracellular signaling pathways in AT II epithelial cells. In addition, inflammatory $\mathrm{CD11b}^{+} \mathrm{Gr}^{+} \mathbf{1}^{+}$myeloid-derived suppressor cells were significantly accumulated but $T$ cells were decreased in the lung and circulation system of doxycycline-treated mice. In vitro, myeloid-derived suppressor cells from the lung suppressed T-cell proliferation and function. As a pathogenic consequence, emphysema was observed in the doxycycline-treated lung in association with up-regulation of matrix metalloproteases. Chronic inflammation and lung injury also induced conversion of bone marrow mesenchymal stem cells into AT II epithelial cells in bitransgenic mice. These findings support that PPAR $\gamma$ and its negatively regulated downstream genes in AT II epithelial cells possess multiple functions to control alveolar homeostasis through inflammatory and noninflammatory mechanisms. (Am J
Pathol 2011, 178:2191-2204; DOI: 10.1016/j.ajpath.2011.01.046 DOI: 10.1016/j.ajpath.2011.01.046)

In previous work, we demonstrated that neutral lipids are essential to maintaining alveolar homeostasis. Blockage of cholesteryl ester and triglyceride metabolism in the lysosomal acid lipase (LAL) knockout mouse model resulted in heterogeneous phenotypes in the lung, including hypercellularity and emphysema. ${ }^{1,2}$ An Affymetrix GeneChip microarray study showed abnormal expression of multiple genes in the lung; in particular, proinflammatory cytokines and chemokines were highly up-regulated in lung alveolar type II (AT II) epithelial cells. ${ }^{2}$ In this mouse model, myeloid-derived lineage cells (especially immature $\mathrm{CD} 11 \mathrm{~b}^{+} \mathrm{Gr}-1^{+}$cells, also called myeloid-derived suppressor cells, or MDSCs) were significantly expanded and infiltrated into the lung and other organs, ${ }^{1-4}$ whereas $T$ cells were dramatically reduced as a result of MDSC suppression and intrinsic defect. ${ }^{4,5}$

LAL hydrolyzes cholesteryl esters and triglycerides to generate free fatty acids and cholesterol in the lysosomes of cells. The downstream metabolites of these compounds (eg, HODEs, HETEs, and $15 d-\mathrm{PGJ}_{2}$ ) serve as hormonal ligands for nuclear receptors, such as peroxisome proliferator-activated receptor- $\gamma$ (PPAR $\gamma$ ). Both PPAR $\gamma$ and retinoid $X$ receptor (RXR) form heterodimer on ligand binding. PPAR $\gamma$ is an anti-inflammatory transcriptional factor by reducing proinflammatory cytokine

Supported by NIH grants HL087001 (H.D.), CA138759 (C.Y.), and HL061803 and HL067862 (C.Y and H.D.).

Accepted for publication January 28, 2011

Supplemental material for this article can be found at http://ajp. amjpathol.org or at doi: 10.1016/j.ajpath.2011.01.046.

Address reprint requests to Hong Du, Ph.D., Division of Human Genetics, Cincinnati Children's Hospital Medical Center, 3333 Burnet Avenue, Cincinnati, OH 45299-3039; or Cong Yan, Ph.D., Center for Immunobiology, Department of Pathology and Laboratory Medicine, IU Simon Cancer Center, Indiana University School of Medicine, 980 W. Walnut Street, Indianapolis, IN 46202. E-mail: hong.du@cchmc.org or coyan@iupui.edu. 
expression. Various experiments demonstrated that PPAR $\gamma$ ligands blocked induction of interleukins IL-1 $\beta$, $\mathrm{IL}-2$, and IL-6, as well as of tumor necrosis factor $\alpha$ $($ TNF- $\alpha){ }^{6-8}$ At the transcriptional level, activated PPAR $\gamma$ effectively blocked the IL-6 downstream signal transduction pathway by inhibiting DNA binding and transcriptional activity of activation of signal transducer and activator of transcription 3 (STAT3), a potent proinflammatory transcription factor. ${ }^{9}$ PPAR $y$ also negatively regulates the expression of proinflammatory and oncogenic apoptosis inhibitor 6 (Api6) and matrix metalloprotease 12 (MMP12), which contribute to emphysema and tumorigenesis in the lung. 2,10,11

We have previously reported that PPAR $\gamma$ is expressed in AT II cells and Clara cells. ${ }^{12}$ We therefore hypothesized that PPAR $\gamma$ in AT II epithelial cells plays important roles in controlling pulmonary inflammation and associated pathogenesis. To test this hypothesis, a doxycycline-controlled CCSP-rtTA/(tetO) $)_{7}-\mathrm{CMV}$-dnPPAR $\gamma$ bitransgenic mouse model was generated. In this model, the dominant-negative PPAR $\gamma$ was overexpressed to inactivate endogenous PPAR $\gamma$ in AT II epithelial cells.

\section{Materials and Methods}

\section{Animal Care}

All scientific protocols involving the use of animals were approved by the Institutional Animal Care and Use Committee (IACUC) of Indiana University School of Medicine and followed guidelines established by the Panel on Euthanasia of the American Veterinary Medical Association. Protocols involving the use of recombinant DNA or biohazardous materials were approved by Biosafety Committee of Indiana University School of Medicine and followed guidelines established by the National Institutes of Health $(\mathrm{NIH})$. Animals were housed under IACUC-approved conditions in a secured animal facility at Indiana University School of Medicine and were regularly screened for common pathogens. Experiments involving animal sacrifice used $\mathrm{CO}_{2}$ narcosis to minimize animal discomfort.

\section{Generation of Doxycycline-Controlled dnPPAR $\gamma$ Transgenic Mice}

To generate the (tetO) $)_{7}-\mathrm{CMV}-\mathrm{dnPPAR} \gamma$ transgenic mouse line, murine dnPPAR $\gamma$ cDNA was amplified by PCR using a downstream primer [5'-AAGGAAAAAAGCGGCCGCTTATCACTTGCTATCGTCGTCCTTGTATCATACAAGTCCTTGTA-3', which contains the Notl site (underlined) and the Flag sequence] and an upstream primer [5'-CTAGACGCGTGCCACCATGGTTGACACACAGATG-3', which contains the Mlu1 site (underlined) and the Kozak sequence]. The PCR product was digested with Mlu1/Notl and subcloned downstream of the cytomegalovirus (CMV) minimal promoter linked to seven Tetresponsive elements at the Mlu1 and Notl sites in the pTRE2 vector (Clontech, Mountain View, CA). The expression cassette containing the CMV minimal promoter, the dnPPAR $\gamma \mathrm{cDNA}$, and the human globin polyadenylation signaling sequence was dissected out and purified for microinjection into FVB/N mice. Founder lines were identified by a pair of primers corresponding to a pTRE2 plasmid sequence (5'-ACGCTGTTTTGACCTCCATAGAAG-3') and to a dnPPAR $\gamma$ cDNA coding region sequence (5'-AACTGTGGTAAAGGGCTTGATGTC-3'). The CCSP-rtTA transgenic mice were provided by Dr. Jay Tichelaar and Jeffery A. Whitsett (Cincinnati Children's Hospital Medical Center, Cincinnati, OH). ${ }^{13}$ CCSP-rtTA/ (tetO) ${ }_{7}-\mathrm{CMV}$-dnPPAR $\gamma$ bitransgenic mice were obtained by crossbreeding CCSP-rtTA transgenic mice and (tetO) $)_{7}-\mathrm{CMV}$-dnPPAR $\gamma$ transgenic mice. As reported originally, ${ }^{13}$ the rat 2.3 -kb CCSP (Clara cell secondary promoter) promoter region showed AT II cell specificity, instead of Clara cell specificity. We had confirmed this previously in the CCSP-rtTA/(tetO) ${ }_{7}-\mathrm{CMV}$-Stat3C bitransgenic mouse model ${ }^{14}$ and in the CCSP-rtTA/(tetO) $)_{7}-\mathrm{CMV}$ MMP12 bitransgenic mouse model. ${ }^{11}$ In general, animals were treated with doxycycline water $(0.5 \mathrm{mg} / \mathrm{mL})$ twice a week starting at 1 month of age, after genotyping.

\section{FACS}

Fluorescence-activated cell sorting (FACS) was performed as described previously. ${ }^{4}$ Briefly, peripheral blood mononuclear cells were obtained after red blood cell lysis with distilled water plus 10× PBS. To prepare cells from the lung, the mouse chest cavity was opened using surgical dissection, and the inferior vena cava and abdominal aorta were clamped. The left atrium was opened by incision, and the right ventricle was infused with $1 \times$ PBS to remove any residual blood in the pulmonary vasculature. The lung was cut into small pieces and placed in RPMI 1640 medium containing 5\% fetal bovine serum, collagenase, and DNase (Sigma-Aldrich, St. Louis, MO). After 40 minutes of digestion at $37^{\circ} \mathrm{C}$, lungs were further disrupted by aspiration through an 18-gauge needle and were suspended in FACS buffer. Approximately $1 \times 10^{6}$ to $2 \times 10^{6}$ cells from various organs in FACS buffer were stained with the cell surface markers anti-CD4, anti-CD8, anti-CD3, anti-B220, anti-CD11c, anti-CD11b, and anti-Gr-1 (eBiosciences, San Diego, CA).

For measurement of intracellular signaling molecules in AT II epithelial cells, cell suspensions from the lungs of doxycycline-treated or untreated CCSP-rtTA/(tetO) $)_{7}-\mathrm{CMV}$ dnPPAR $\gamma$ bitransgenic mice were fixed with $2 \%$ formaldehyde. After 20 minutes at room temperature, fixation samples were resuspended in methanol at a final $90 \%$ concentration for 2 hours at $4{ }^{\circ} \mathrm{C}$, and then washed and resuspended in $200 \mu \mathrm{L} 1 \times$ permeabilization buffer. Cell suspensions were labeled with SP-C antibody and the primary phospho-specific antibodies at $4^{\circ} \mathrm{C}$ overnight, then washed in $1 \times$ PBS containing $4 \%$ fetal bovine serum and labeled using the secondary antibody. Anti-phosphoP44/42 (Erk1/2), anti-phospho-P38, anti-phospho-NF- $k$ B, anti-phospho-Stat1, anti-phospho-Stat2, anti-phosphoStat3, anti-phospho-Stat4, anti-phospho-Stat5, and antiphospho-Stat6 antibodies were purchased from Cell Signaling Technology (Danvers, MA). SP-C antibody (FL-197) was purchased from Santa Cruz Biotechnology (Santa Cruz, 
CA). Anti-Flag polyclonal antibody (F7425) was purchased from Sigma-Aldrich.

For measurement of intracellular signaling molecules in MDSCs, cell suspensions from bone marrow, spleen, blood, and lung of doxycycline-treated or untreated CCSP-rtTA/(tetO) $)_{7}-\mathrm{CMV}$-dnPPAR $\gamma$ bitransgenic mice were stained with CD11b and GR-1 antibodies, and then fixed with $2 \%$ formaldehyde. After 10 minutes at $37^{\circ} \mathrm{C}$, fixation samples were resuspended in methanol at a final 90\% concentration for 30 minutes at $4^{\circ} \mathrm{C}$. Cell suspensions were labeled with phospho-specific antibodies at $4^{\circ} \mathrm{C}$ overnight and then analyzed by flow cytometry. Anti-phospho-P44/42 (Erk1/2), anti-phospho-P38, anti-phospho-NF-кB, antiphospho-Akt, and anti-phospho-Stat3 antibodies were purchased from Cell Signaling Technology.

Cells were analyzed on an LSR II flow cytometer (BD Biosciences, San Jose, CA). Data were analyzed using BD FACStation software (BD CellQuest Pro version 5.2.1; $\mathrm{BD}$ Biosciences). The total number of positive cells was calculated as gated viable cells. Isotype controls IgG1, IgG2a, and IgG2b were included in all experiments. Quadrants were assigned using isotype controls.

\section{Western Blot}

Cells from the lung of doxycycline-treated or untreated CCSP-rtTA/(tetO) ${ }_{7}$-dnPPAR $\gamma$ bitransgenic mice were prepared as described above. Protein extracts were prepared in radioimmunoprecipitation assay (RIPA) buffer and fractionated on a polyacrylamide gel (Invitrogen, Carlsbad, CA). After transferring to the immunoblot polyvinylidene difluoride membrane, anti-PPAR $\gamma$ antibody was used to hybridize with the membrane. Protein bands were visualized with a Vectastain Elite ABC kit (Vector Laboratories, Burlingame, CA). Anti-PPAR $\gamma$ antibody (SC-7196) was purchased from Santa Cruz Biotechnology.

\section{Isolation of $\mathrm{CD} 4^{+} \mathrm{T}$ Cells and MDSCs}

To purify $\mathrm{CD} 4^{+} \mathrm{T}$ cells, erythrocyte-depleted splenocytes were stained with anti-CD4 microbeads and passed over a mass spectrometry column according to the manufacturer's instructions (Miltenyi Biotec, Auburn, CA). To purify $\mathrm{CD} 11 \mathrm{~b}^{+} \mathrm{Gr}-1^{+}$MDSCs, single cells from the bone marrow, spleen, and lung were stained with anti-Gr- $1^{+}$biotin antibodies, followed by positive magnetic selection using anti-biotin microbeads according to the manufacturer's instructions (Miltenyi Biotec). The purity of the MDSC population was typically $>90 \%$.

\section{In Vitro MDSC Suppression Assay}

For the proliferation study, the sorted $\mathrm{CD} 4^{+} \mathrm{T}$ cells from wild-type spleen were labeled with $1 \mu \mathrm{mol} / \mathrm{L}$ carboxyfluorescein diacetate succinimidyl diester (CFSE; Molecular Probes, Eugene, Oregon) at $37^{\circ} \mathrm{C}$ for 10 minutes. Cells were pelleted and resuspended in complete medium for 40 minutes, followed by washing twice in PBS. CFSElabeled $\mathrm{CD}^{+}{ }^{+} \mathrm{T}$ cells were cultured in 96-well flat-bottom plates coated with anti-CD3 monoclonal antibody (mAb) (2 $\mu \mathrm{g} / \mathrm{mL})$ and anti-CD28 $\mathrm{mAb}(5 \mu \mathrm{g} / \mathrm{mL})$. Purified MDSCs from bone marrow, spleen, and lung of doxycyclinetreated or untreated CCSP-rtTA/(tetO) ${ }_{7}-\mathrm{CMV}$-dnPPAR $\gamma$ bitransgenic mice were added into wells. The ratio of MDSCs to $C D 4^{+}$T cells was 1:5. After 4 days, cells were harvested, stained with APC-labeled anti-CD4 mAb (eBiosciences), and analyzed by flow cytometry.

For the CD69 expression study, MDSCs from the bone marrow, spleen, and lung of doxycycline-treated or untreated bitransgenic mice and wild-type $T$ splenocytes were cocultured in 96-well plates coated with anti-CD3 $\mathrm{mAb}(2 \mu \mathrm{g} / \mathrm{mL})$ and anti-CD28 mAb $(5 \mu \mathrm{g} / \mathrm{mL})$ for 48 hours. Cells were harvested, stained with anti-CD4-APC $\mathrm{mAb}$ and anti-CD69-PEcy7 mAb (eBiosciences), and analyzed by flow cytometry. The expression levels of IL-2, $\mathrm{IL}-4$, and IFN- $\gamma$ in the culturing supernatants were measured using enzyme-linked immunosorbent assay (ELISA) kits according to the manufacturer's instructions (BD Biosciences).

\section{Alveolar Type II Epithelial Cell Purification}

AT II epithelial cells were purified from wild-type mice and doxycycline-treated or untreated CCSP-rtTA/(tetO) ${ }_{7}^{-}$ CMV-dnPPAR $\gamma$ bitransgenic mice, as described previously. ${ }^{15}$ After purification, AT II epithelial cells were stained with anti-CD11b and Gr-1 antibodies to make sure there was no contamination by macrophages or neutrophils.

\section{Reverse Transcription and Real-Time PCR}

For reverse transcription reactions, total RNAs were extracted from whole lungs or AT II epithelial cells of doxycycline-treated or untreated CCSP-rtTA/(tetO) ${ }_{7}-\mathrm{CMV}$ dnPPAR $\gamma$ bitransgenic mice using a Qiagen RNeasy mini kit according to the manufacturer's instruction (Qiagen, Valencia, CA). RNAs $(2 \mu \mathrm{g})$ were reversely transcribed using Taqman Reverse Transcription Reagent (Applied Biosystems, Branchburg, NJ) in a GeneAmp 9700 thermocycler (Applied Biosystems, Foster City, CA) with cycling conditions as recommended by the manufacturer: $25^{\circ} \mathrm{C}$ for 10 minutes, $48^{\circ} \mathrm{C}$ for 30 minutes, and $95^{\circ} \mathrm{C}$ for 5 minutes. All reactions were performed using a TaqMan reverse transcription kit (Applied Biosystems).

For real-time PCR, $2 \mu \mathrm{L}$ of cDNA was amplified by a pair of sequence-specific DNA oligonucleotide primers for each molecule in a $50-\mu \mathrm{L}$ reaction mixture containing SYBR Green PCR master mix (Applied Biosystems). The housekeeping gene GAPDH (glyceraldehyde-3-phosphate dehydrogenase) was an endogenous control in parallel PCR reactions. The reactions were analyzed using a relative quantification assay and a 7500 system sequence detection software package (7500 real-time PCR system version 1.3.1; Applied Biosystems). The default cycling protocol for this software was $50^{\circ} \mathrm{C}$ for 2 minutes, $95^{\circ} \mathrm{C}$ for 10 minutes, and 40 cycles of $95^{\circ} \mathrm{C}$ for 15 seconds, and $60^{\circ} \mathrm{C}$ for 1 minute. Relative expression was determined by the $2^{\Delta \Delta C t}$ method, in which $\Delta \Delta \mathrm{C}_{\mathrm{t}}=\Delta \mathrm{C}_{\mathrm{t}(+ \text { Dox })}-\Delta \mathrm{C}_{\mathrm{t}(- \text { Dox })} \cdot \Delta \mathrm{C}_{\mathrm{t}}$ represents the PCR cycle threshold $\left(\mathrm{C}_{t}\right)$ of a testing molecule normalized by the $\mathrm{C}_{\mathrm{t}}$ of $\mathrm{GAPDH}$, as $\Delta \mathrm{C}_{\mathrm{t}}=\mathrm{C}_{\mathrm{t} \text { (testing }}$ 
2194 Wu et al

AJP May 2011, Vol. 178, No. 5

Table 1. Primers for Real-Time PCR

\begin{tabular}{|c|c|c|}
\hline Gene & Forward primer & Reverse primer \\
\hline$m I F N-\alpha$ & $5^{\prime}$-AAGGACAGGAAGGATTTTGGATT-3' & 5'-GAGCCTTCTGGATCTGTTGGTT-3' \\
\hline$m I F N-\gamma$ & $5^{\prime}-$ CAAGGCGAAAAAGGATGCAT-3' & $5^{\prime}-$ CTGGACCTGTGGGTTGTTGAC $-3^{\prime}$ \\
\hline$m / L-1 \beta$ & $5^{\prime}-$ TTGACGGACCCCAAAAGATG-3' & $5^{\prime}$ - CAGGACAGCCCAGGTCAAA-3' \\
\hline$m / L-6$ & 5'-GAGGCTTAATTACACATGTTC-3' & 5'-TGCCATTGCACAACTCTTTTCT-3' \\
\hline$m / L-13$ & 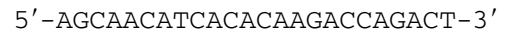 & $5^{\prime}-\mathrm{CCAGGTCCACACTCCATACCA-3^{ \prime }}$ \\
\hline$m M M P-2$ & $5^{\prime}$-GAGGCTGACATCATGATCAACTTT- $3^{\prime}$ & $5^{\prime}$-GCCATCAAATGGGTATCCATCT-3' \\
\hline$m M M P-7$ & 5'-TGAGGACGCAGGAGTGAACTT-3' & 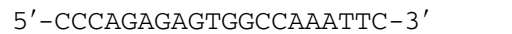 \\
\hline mMMP-8 & $5^{\prime}$-CTCAAGAGACCATGGTGACAATTC-3' & $5^{\prime}-$ AAGGCATGGGCAAGGATTC- $3^{\prime}$ \\
\hline mMMP-9 & 5'-GAGGCTGACATCATGATCAACTTT- -3' & $5^{\prime}$-GCCATCAAATGGGTATCCATCT-3' \\
\hline$m M M P-12$ & 5'-TGGTATTCAAGGAGATGCACATTT-3' & 5'-GGTTTGTGCCTTGAAAACTTTTAGT-3' \\
\hline$m T N F-\alpha$ & $5^{\prime}$-CCCCAAAGGGATGAGAAGTTC-3' & $5^{\prime}$-TGAGGGTCTGGGCCATAGAA-3' \\
\hline GAPDH & $5^{\prime}-$ GGCCATCAAGCCAGAGCTT-3' & $5^{\prime}$-CCAAACCATCACTGACACTCAGA-3' \\
\hline
\end{tabular}

molecule $)-\mathrm{C}_{\mathrm{t}(\mathrm{GAPDH})}$. Primers for real-time PCR are listed in Table 1.

\section{Bronchioalveolar Lavage Fluid Collection and Kwik-Diff Staining}

Bronchioalveolar lavage fluid (BALF) was collected by 1-mL $1 \times$ PBS wash and repeated three times. Cells were centrifuged at $1000 \mathrm{rpm}$ on a Thermo CR4i Centrifuge (Asheville, $\mathrm{NC)}$ for 5 minutes and resuspended into $0.5 \mathrm{~mL} 1 \times$ PBS. Total cell number in BALF was determined by hemocytometry. The same volume of cell suspension was spun onto slides using a centrifuge and stained with a Kwik-Diff stain kit (Thermo Shandon, Pittsburgh, PA).

\section{Cytokine Measurement by ELISA}

BALF was obtained from the lungs of CCSP-rtTA/(tetO) $7^{-}$ CMV-dnPPAR $\gamma$ bitransgenic mice. The expression levels of IL-1 $\beta, \mathrm{IL}-6$, and TNF- $\alpha$ in BALF were measured using DuoSet ELISA kits for mouse IL- $1 \beta$, IL- 6 , and TNF- $\alpha$ according to the manufacturer's instructions (R\&D Systems, Minneapolis, MN).

\section{ChIP Assay}

Following a procedure described previously, ${ }^{16}$ single cells were isolated from the lungs of 2-month doxycycline-treated or untreated CCSP-rtTA/(tetO) $)_{7}-\mathrm{CMV}-$ dnPPAR $\gamma$ bitransgenic mice. Proteins were cross-linked to DNA by adding formaldehyde directly to the RPMI 1640 culture medium to a final concentration of $1 \%$, followed by incubation for 10 minutes at room temperature. The cells were washed with $1 \times$ PBS three times and then lysed with SDS lysis buffer (0.1\% SDS, $3 \mathrm{mmol} / \mathrm{L}$ EDTA, $25 \mathrm{mmol} / \mathrm{L}$ Tris $\mathrm{pH} 8.1,1 \times$ protease inhibitor cocktail). Cells were sonicated for $10 \mathrm{sec}-$ onds three times at 30 -second intervals. A fraction of $1 \%$ sonicated chromatin was saved from each sample for input normalization of real-time PCR. The remaining chromatin samples were incubated with $20 \mu \mathrm{g}$ of anti-Flag polyclonal antibody (Sigma-Aldrich) overnight at $4^{\circ} \mathrm{C}$. Protein $\mathrm{A}$ agarose beads were added to adsorb the immunocomplexes, with rotating at $4^{\circ} \mathrm{C}$ for 2 hours. DNA-protein immunocomplexes were eluted from the beads with chromatin immunoprecipitation (ChIP) elution buffer (1\% SDS, $0.1 \mathrm{~mol} / \mathrm{L}$
$\mathrm{NaHCO}_{3}$ ) and were de-crosslinked at $65^{\circ} \mathrm{C}$ for 4 hours. DNA was isolated by chloroform-phenol extraction. For realtime PCR, $2 \mu \mathrm{L}$ of DNA as described above was amplified by a pair of sequence-specific DNA oligonucleotide primers for each gene promoter (as listed below) in a $50-\mu \mathrm{L}$ reaction mixture containing SYBR Green PCR master mix (Applied Biosystems). The reactions were analyzed using a relative quantification assay and 7500 system software. All PCR reactions were normalized by input DNA fraction according to $\Delta \mathrm{C}_{\mathrm{t}}=\mathrm{C}_{\mathrm{t} \text { (testing) }}-\left(\mathrm{C}_{\mathrm{t} \text { (input) }}-\log _{2 \text { (input dilution factor) }}\right.$ as described by the manufacturer (ChampionChIP qPCR Primers User Manual; SABiosciences, Frederick, MD).

Based on the DNA binding sequence (5'-(A/G)GG(T/ G)CA(A/G)AGG(T/G)CA-3') for PPAR $\gamma$, the putative PPAR $\gamma$ binding sites were identified on the promoters of the Api6 (ENSMUSG00000015854), IL-1 $\beta$ (ENSMUSG00000027398), IL-6 (ENSMUSG00000025746), MMP12 (ENSMUSG00000049723), and TNF- $\alpha$ (ENSMUSG00000024401) genes according to the Ensembl database (http://www.ensembl. org/index.html), using MacVector 8.1.2 software (MacVector, Cary, NC).

Primers for ChIP-real-time PCR were as follows: mApi-6: 5'-GGAAGCTGGTTGAAGGTAGGAA-3' (upstream) and 5'-GTAAGTCACGATTGTGGCATCTATCT-3' (downstream); mIL-1 $\beta:$ 5'-CACTATCTGCCACCCCTTGAC-3' (upstream) and 5'-GAAGAGGCTATTGCTACCCTGAAA-3' (downstream); mIL-6: 5'-TGGGATCAGCACTAACAGATAAGG-3' (upstream) and 5'-TGGTCTCTTGGCTATCTTCTTAGTTAAG-3' (downstream); mMMP12: 5'-GCAGAAAAATTGAAATGGGTAAAGA-3' (upstream) and 5'-TGGGTTGCTTTGGGAGGTATT-3' (downstream); mTNF- $\alpha$ : $5^{\prime}$-CCCAGATTGCCACAGAATCC-3' (upstream) and 5'-CCTACACCTCTGTCTCGGTTTCTT-3' (downstream).

\section{Lung Histology and Morphometry}

The trachea was cannulated and the cannula was tied firmly in place. The lungs were filled through the trachea with $4 \%$ paraformaldehyde in PBS at $20 \mathrm{~cm} \mathrm{H}_{2} \mathrm{O}$ pressure by gravity and were maintained overnight at $4^{\circ} \mathrm{C}$. The lungs were monitored for leakage during this procedure at $4^{\circ} \mathrm{C}$ for approximately 24 hours. Only lungs that did not leak were used for further study. The lungs were washed with PBS and dehydrated through an ethanol series, followed by paraffin embedding. Sections (5 $\mu \mathrm{m})$ were mounted on glass slides and deparaffinized. The adult 
lung slides were washed in a series of xylene and ethanol to remove paraffin from the tissues. Multiple sections from each lung were stained with H\&E. For quantitative characterization, images at $\times 20$ original magnification were transferred by video camera to a computer for viewing on-screen. The measurements of alveolar number, alveolar mean cord length $(\mathrm{Lm})$, alveolar area, alveolar sphere surface area, and alveolar volume were determined by MetaMorph imaging software version 7.1.2.0 (Molecular Devices, Sunnyvale, CA) by selecting appropriate functions. Twenty randomly selected microscopic fields of respiratory alveoli were analyzed.

\section{MMP Activity}

BALF was obtained from the lungs of doxycycline-treated or untreated CCSP-rtTA/(tetO) $)_{7}$-CMV-dnPPAR $\gamma$ mice for MMP activity assay. MMP9 and MMP12 specific activities were measured by fluorescence quenched substrate cleaving using a SensoLyte 490 MMP assay kit (AnaSpec, San Jose, CA). This kit was optimized to detect the activities of MMPs in biological samples using a fluorescence quenched substrate (EDANS/DabcylPlus FRET peptide; AnaSpec) at excitation and emission wavelengths of 340 $\mathrm{nm}$ and $490 \mathrm{~nm}$, respectively. Each BALF sample was incubated with $5 \mu \mathrm{L} 1 \mathrm{mmol} / \mathrm{L}$ 4-aminophenylmercuric acetate (APMA) for 2 hours at $37^{\circ} \mathrm{C}$ to activate MMPs. Samples $(50 \mu \mathrm{L})$ were then added to a 96-well plate, and a standard curve was set up using a serial dilution of purified MMP9 and MMP12 protein (AnaSpec) at concentrations of $1.6 \mathrm{ng} / \mu \mathrm{L}, 0.8 \mathrm{ng} / \mu \mathrm{L}, 0.4 \mathrm{ng} / \mu \mathrm{L}, 0.2 \mathrm{ng} / \mu \mathrm{L}, 0.1$ $\mathrm{ng} / \mu \mathrm{L}, 0.05 \mathrm{ng} / \mu \mathrm{L}$, and $0.0125 \mathrm{ng} / \mu \mathrm{L}$. MMP12 substrate solution (50 $\mu \mathrm{L}$ per well, $1 \times$ ) was added to the samples and the standards. The plate was mixed gently and incubated at room temperature for 1 hour and protected from light. Stop solution from AnaSpec $(50 \mu \mathrm{L})$ was added to each well, and the fluorescence intensity was measured using a VICTOR3 fluorescence plate reader (Perkin Elmer, Waltham, MA) at $490 \mathrm{~nm}$ after excitation at $340 \mathrm{~nm}$. MMP9 or MMP12 purified enzyme (Sigma-Aldrich) was used as positive control.

\section{Bone Marrow Stem Cell Injection and Double-Immunofluorescence Staining}

For bone marrow mesenchymal stem cells (BMSCs), we followed a procedure described previously. ${ }^{17}$ BMSCs were isolated from femur and tibia of hSP-B 1.5kb lacZ transgenic mice, 2 to 3 months old, ${ }^{18}$ and then were cultured in Mesencult MSC basal medium (StemCell Technologies, Vancouver, $\mathrm{BC}$, Canada) at $37^{\circ} \mathrm{C}$ with $5 \% \mathrm{CO}_{2}$. After 1 day, the unattached cells were discarded and, for attached BMSCs, the medium was completely replaced. Thereafter, half the medium was changed every 3 days until confluence was reached. BMSCs were passaged five to six times with split, to amplify the cell population. Each passage took 1 week to reach confluence.

Cultured BMSCs were harvested and resuspended in $1 \times$ PBS $\left(1 \times 10^{6} \mathrm{BMSC} / 100 \mu \mathrm{L}\right)$. Each mouse was infused with $200 \mu \mathrm{L}$ BMSCs through the tail vein. The same procedure was repeated 2 weeks later. After 8 weeks of initial injection, AT II epithelial cells were isolated from recipient mice and double-stained with rabbit anti-proSP-C antibody and mouse anti- $\beta$-galactosidase antibody. A Cy2-conjugated donkey anti-rabbit IgG and a Cy3-conjugated donkey anti-mouse IgG were used as the secondary antibodies (Jackson ImmunoResearch, West Grove, PA). Labeled cells were analyzed by fluorescence microscopy or flow analysis. DAPI was used for nuclear staining.

\section{Statistical Analysis}

Data are reported as means $\pm S D$ of at least three independent experiments. A paired Student's $t$-test or analysis of variance was used to evaluate the significance of the differences. Statistical significance was set at $P<0.05$.

\section{Results}

\section{Generation of CCSP-rtTA(tetO) $)_{7}-C M V-d n P P A R \gamma$ Bitransgenic Mice}

A doxycycline-inducible bitransgenic mouse model was generated to specifically direct dnPPAR $\gamma$ expression in lung epithelial cells. In this system, a previously established CCSP-rtTA transgenic mouse line ${ }^{13}$ was crossbred with a newly generated (tetO) $)_{7}-\mathrm{CMV}-\mathrm{dnPPAR} \gamma$ transgenic mouse line. The PPAR $\gamma$ mutant form contains two substitutions ( $L 468 \mathrm{~A}$ and $\mathrm{E} 471 \mathrm{~A}$ ) in the AF-2 domain and acts as a dominant negative $(\mathrm{dn})$ form. ${ }^{19}$ A Flag sequence was added at the $C$ terminus of the dnPPAR $\gamma$ cDNA to distinguish it from the endogenous PPAR $\gamma$ molecule. CCSPrtTA/(tetO) ${ }_{7}$-CMV-dnPPAR $\gamma$ bitransgenic mice were successfully obtained, as detected by PCR using specific primers and mouse tail DNA (Figure 1A). Induction of dnPPAR $\gamma$ mRNA expression was achieved by doxycycline treatment for 1 month, monitored by real-time PCR assay in CCSPrtTA/(tetO) $)_{7}$-CMV-dnPPAR $\gamma$ bitransgenic mice, compared with untreated mice (Figure 1B).

Western blot analysis with PPAR $\gamma$ antibody showed induced expression of dnPPAR $\gamma$ over PPAR $\gamma$ in the lung of doxycycline-treated CCSP-rtTA/(tetO) $)_{7}$-CMV-dnPPAR $\gamma$ bitransgenic mice (Figure 1C). A basal level of endogenous PPAR $\gamma$ expression was also detected in the lung of doxycycline-untreated CCSP-rtTA/(tetO) $)_{7}$-CMV-dnPPAR $\gamma$ bitransgenic mice. To further assess whether dnPPAR $\gamma_{-}$ Flag fusion protein was induced in AT II epithelial cells, flow cytometry was performed to double-label lung single cells using anti-SP-C (AT II epithelial cell marker) and anti-Flag antibodies. Expression of the dnPPAR $\gamma$-Flag fusion protein was readily detected in SP-C ${ }^{+}$AT II epithelial cells using an anti-Flag antibody in doxycycline-treated CCSP-rtTA/ $(\text { tetO) })_{7}-\mathrm{CMV}$-dnPPAR $\gamma$ bitransgenic mice, but not in alveo-


fusion protein was detected in SP-C ${ }^{+}$AT II epithelial cells from doxycycline-untreated bitransgenic mice. The same negative observation was also made in CCSP-rtTA single transgenic mice (see Supplemental Figure S1A at $h$ ttp://ajp. amjpathol.org). 
A



B

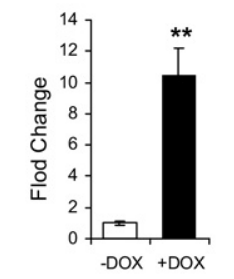

D



Flag



Figure 1. Generation of doxycycline-inducible CCSP-rtTA/(tetO) $)_{7}-\mathrm{CMV}$ dnPPAR $\gamma$ bitransgenic mice. A: Construct maps and genotyping for CCSPrtTA transgenic mice, (TetO) $)_{7}$-CMV-dnPPAR $\gamma$ transgenic mice, and CCSP$\mathrm{rtTA} /(\text { tetO) })_{7}$-CMV-dnPPAR $\gamma$ bitransgenic mice. Lane 1, DNA molecular marker; lane 2, CCSP-rtTA transgenic mouse; lane 3, (tetO) $)_{7}$-CMV-dnPPAR $\gamma$ transgenic mouse; lane 4, CCSP-rtTA/(tetO) $)_{7}$-CMV-dnPPAR $\gamma$ bitransgenic mouse. B: Real-time PCR analysis of the dnPPAR $\gamma$ mRNA expression level in the lungs of CCSP-rtTA/(tetO) $)_{7}$-CMV-dnPPAR $\gamma$ bitransgenic mice that were treated with doxycycline ( + DOX) or untreated ( - DOX) for 4 months ( $n=$ 4 to 6$)$. Data are reported as means \pm SD. ${ }^{* *} P<0.01$. C: Western blot analysis of PPAR $\gamma$ and dnPPAR $\gamma$ protein expression levels in the lungs of doxycycline-treated (+DOX) or untreated (-DOX) CCSP-rtTA/(tetO) $)_{7}$-CMV dnPPAR $\gamma$ bitransgenic mice. MW, molecular weight marker. D: Expression of the dnPPAR $\gamma$-Flag fusion protein in the AT II epithelial cells from the lungs of wild-type mice (WT), untreated bitransgenic mice (-DOX), or doxycycline-treated ( + DOX) bitransgenic mice ( $n=4$ to 6$)$ assessed by flow cytometry. Treatment duration: 4 months. The cells were double-labeled with anti-Flag and anti-SP-C antibodies (AT II marker). CD11b is a macrophage marker and served as the negative control. Data are reported as means $\pm \mathrm{SD} .{ }^{* *} P<0.01$.

\section{Overexpression of dnPPAR Induces Emphysema in the Lung of Bitransgenic Mice}

To assess pathogenic phenotypes in the lung as a result of dnPPAR $\gamma$ overexpression in AT II epithelial cells, CCSP-rtTA/(tetO) $)_{7}-\mathrm{CMV}$-dnPPAR $\gamma$ bitransgenic mice with 4 months of doxycycline treatment were investigated by histological analysis. Histopathological analysis revealed emphysema in the lung of doxycycline-treated CCSP-rtTA/(tetO) $)_{7}$-CMV-dnPPAR $\gamma$ bitransgenic mice (Figure 2A). Quantitative analysis with MetaMorph imaging software showed that alveolar numbers of doxycycline-treated CCSP-rtTA/(tetO) $)_{7}-\mathrm{CMV}-\mathrm{dnPPAR} \gamma$ mice $(65 \pm 9)$ were much less than those of untreated bitrans- genic mice (122 \pm 13$)$ (Figure 2B). The mean cord length $(\mathrm{Lm})$, alveolar area, alveolar sphere surface area, and alveolar volume were all significantly increased in doxycycline-treated bitransgenic mice, compared with untreated bitransgenic mice (Figure $2 \mathrm{C}$ ).

MMPs are major tissue remodeling enzymes. Their upregulation is associated with emphysema formation and progression. ${ }^{20}$ In 4-month doxycycline-treated CCSPrtTA/(tetO) $)_{7}-\mathrm{CMV}$-dnPPAR $\gamma$ bitransgenic mice, mRNA expression levels of MMP2, $-7,-8,-9$, and -12 were highly induced in AT II epithelial cells (Figure 2D). No change was observed in CCSP-rtTA single transgenic mice (see Supplemental Figure S1B at http://ajp.amjpathol.org). In our previous study, at least MMP12 was demonstrated to be a direct PPAR $\gamma$ negatively regulated downstream target gene in lung epithelial cells. ${ }^{2}$ To determine whether MMP concentrations were increased in BALF, enzymatic activities of MMP9 and MMP12 were analyzed. BALF from 4-month doxycycline-treated and untreated CCSP$\mathrm{rtTA} /(\mathrm{tetO})_{7}-\mathrm{CMV}$-dnPPAR $\gamma$ bitransgenic mice was collected. The enzymatic activities were analyzed by cleavage of a fluorescence quenched substrate. The MMP9 specific activity was significantly higher in doxycyclinetreated bitransgenic mice $(1.93 \pm 0.1 \mathrm{ng} / \mu \mathrm{L})$ than in untreated control mice $(0.30 \pm 0.08 \mathrm{ng} / \mu \mathrm{L})$. The MMP12 specific activity was also significantly higher in doxycycline-treated bitransgenic mice $(1.52 \pm 0.14 \mathrm{ng} / \mu \mathrm{L})$ than in untreated control mice $(0.22 \pm 0.03 \mathrm{ng} / \mu \mathrm{L}$ ) (Figure 2D). No statistically significant change was observed in CCSP-rtTA single transgenic mice (see Supplemental Figure S1C at http://ajp.amjpathol.org). Thus, MMP synthesis and secretion were induced by inactivation of PPAR $\gamma$ in AT II epithelial cells that contributed to emphysema formation.

\section{ChIP of Proinflammatory Genes in AT II Epithelial Cells of Bitransgenic Mice}

Because PPAR $y$ is an anti-inflammatory molecule, it was important to evaluate whether the proinflammatory molecules were up-regulated in CCSP-rtTA/(tetO) $)_{7}-\mathrm{CMV}$ dnPPAR $\gamma$ bitransgenic mice. These molecules are potentially important for triggering and recruiting immune cells into the lung to initiate inflammation and emphysema. PPAR $y$ binds to specific DNA sites (PPAR E) on the promoters after ligand binding and prevents transcriptional events of proinflammatory molecules. Because the Api6, IL-1 $\beta, I L-6, M M P 12$, and TNF- $\alpha$ genes are downstream of PPARG, ${ }^{6-8}$ it is possible that overexpression of dnPPAR $\gamma$ in doxycycline-treated CCSP-rtTA/(tetO) $7^{-}$ $\mathrm{CMV}$-dnPPAR $\gamma$ bitransgenic mice interferes with endogenous PPAR $\gamma$ function at the transcriptional level by competition, with DNA binding on the same PPAR E sites of these genes' promoters. To test this assumption, ChIP assay was performed to investigate the association between dnPPAR $\gamma$ and PPAR E sites within the Api6, IL-1 $\beta$, IL-6, MMP12, and TNF- $\alpha$ promoters in 2-month doxycycline-treated or untreated CCSP-rtTA/(tetO) ${ }_{7}-\mathrm{CMV}$ dnPPAR $\gamma$ bitransgenic lung. Pathologically, overexpression of MMP12 and Api6 in mice caused chronic 
A



C

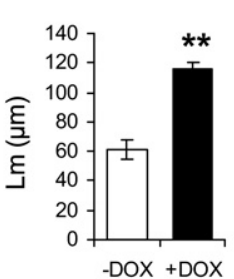

B



$\mathrm{D}$

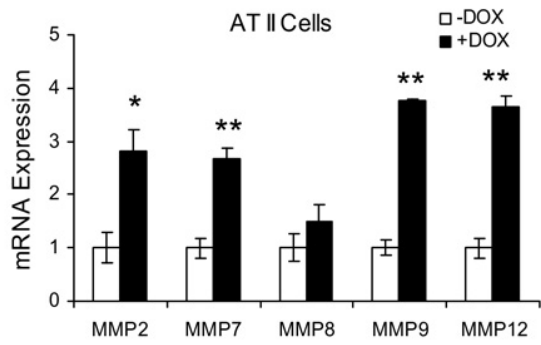

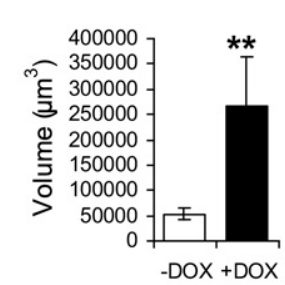



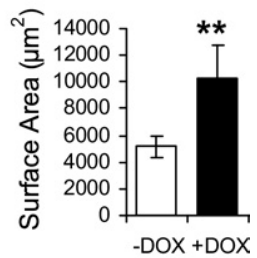

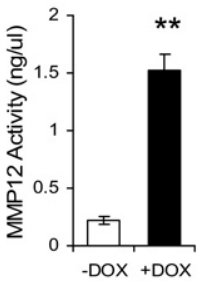

Figure 2. Histopathology and up-regulation of MMPs in the lung of CCSP-rtTA/(tetO) $)_{7}-\mathrm{CMV}$ dnPPAR $\gamma$ bitransgenic mice. A: H\&E staining of lung tissue sections from representative doxycycline-treated or untreated CCSP-rtTA/(tetO) $)_{7}-\mathrm{CMV}$ dnPPAR $\gamma$ bitransgenic mice with emphysema Treatment duration: 4 months. B: Quantitative measurement of the alveolar numbers by MetaMorph imaging software. Data are reported as means $\pm \mathrm{SD}(n=6) .{ }^{* * *} P<0.01$. C: Quantitative measurement of mean cord length (Lm), alveolar area, alveolar volume, and alveolar sphere surface area were determined by MetaMorph imaging software. Data are reported as means $\pm \mathrm{SD}$ $(n=6) .{ }^{* *} P<0.01$. D: MMP mRNAs from AT II epithelial cells of doxycycline-treated or untreated CCSP-rtTA/(tetO) ${ }_{7}$-CMV-dnPPAR $\gamma$ bitransgenic mice were analyzed by real-time PCR ( $n=4$ to 6 ). The enzymatic activities of MMP) and MMP12 in BALF from doxycycline-treated or untreated CCSP-rtTA/(tetO) $)_{7}$-CMV-dnPPAR $\gamma$ bitransgenic mice were analyzed by an MMP assay kit ( $n=4$ to 6$)$. Treatment duration: 4 months Data are reported as means $\pm \mathrm{SD} .{ }^{*} P<0.05$ ${ }_{* *}^{*} P<0.01 ;-$ DOX, doxycycline-untreated bitransgenic mice. +DOX, doxycycline-treated bitransgenic mice. inflammation, emphysema, and bronchioalveolar adenocarcinoma. ${ }^{10,11}$ The putative PPAR $E$ sites within the promoters of Api6, IL-1 $\beta, I L-6, M M P 12$, and TNF- $\alpha$ were identified (Figure 3A). Anti-Flag polyclonal antibody was used to immunoprecipitate the dnPPAR $\gamma$-Flag/DNA complex. In doxycycline-treated mice, the signals of precipitated promoter DNA were stronger than those of untreated controls, according to quantitative real-time PCR analysis (Figure 3B). The results showed that dnPPAR $\gamma$-Flag fusion protein was able to bind to the promoters of these proinflammatory genes.

\section{Overexpression of Proinflammatory Molecules in the Lung of Bitransgenic Mice}

To determine whether dnPPAR $\gamma$ overexpression indeed up-regulates proinflammatory cytokines in vivo, total RNAs were purified from AT II epithelial cells of 2-month doxycycline-treated or untreated CCSP-rtTA/(tetO) $)_{7}$ CMV-dnPPAR $\gamma$ bitransgenic mice. The expression levels of multiple cytokines were quantitatively determined by real-time PCR. Among these, mRNA expression levels of IFN- $\alpha$, IFN- $\gamma$, IL-1 $\beta$, IL-6, IL-13, and TNF- $\alpha$ in doxycycline-treated mice were increased, compared with doxycycline-untreated mice (Figure 4A). No change was observed in CCSP-rtTA single transgenic mice (see Supplemental Figure S1D at http://ajp.amjpathol.org). In BALF, protein concentrations of secreted IL-1 $\beta$, IL-6, and TNF- $\alpha$ were steadily increased as measured by ELISA, compared with untreated mice (Figure 4B).

\section{Overexpression of dnPPAR Increases Myeloid Cell Infiltration in the Lung of Bitransgenic Mice}

Up-regulation of proinflammatory cytokines suggests that overexpression of dnPPAR $\gamma$ may induce inflammation that contributes to emphysema. To determine whether overexpression of dnPPAR $\gamma$ induces inflammatory cell infiltration in the lung of CCSP-rtTA/(tetO) $)_{7}-\mathrm{CMV}$ dnPPAR $\gamma$ bitransgenic mice as a result of proinflammatory cytokine up-regulation, peripheral blood mononuclear cells and lung mononuclear cells were isolated from doxycycline-treated or untreated mice (treatment duration of 1, 4, or 8 months) and stained with fluorochrome-conjugated anti-mouse CD11b (for monocytes) and Gr-1 (for neutrophils) antibodies for FACS analysis. Compared with doxycycline-untreated CCSP-rtTA/(tetO) $)_{7}-\mathrm{CMV}-$ dnPPAR $\gamma$ bitransgenic mice, the absolute numbers and (excepting 1 month treatment) percentage numbers of immature $\mathrm{CD} 11 \mathrm{~b}^{+} \mathrm{GR}-1^{+} \mathrm{MDSC}$ s were steadily increased in the blood and lung of 1-month, 4-month, and 8-month doxycycline-treated mice (Figure 5, A and B). No change was observed in CCSP-rtTA single transgenic mice (see Supplemental Figure S1E at http://ajp.amjpathol.org). Pathologically, clustered inflammatory cell accumulation was observed in some lung areas of doxycycline-treated CCSP-rtTA/(tetO) $)_{7}-\mathrm{CMV}$-dnPPAR $\gamma$ bitransgenic mice (Figure $5 \mathrm{C}$ ). IHC showed positive staining of myeloidspecific Mac2 antibody on these cells. Kwik-Diff staining showed significant increase of inflammatory cells in the BALF of doxycycline-treated mice (Figure 5D), which resembled the morphological characteristics of MDSCs. 4,21,22 This suggests that myeloid cells were blocked 


\section{A}

\section{Api6:}

$-400 \quad 5^{\prime}$-GTGTTAGGCTTCTGACCAGCACTCGGGAAGCTGGTTGAAGGTAGGAAAGC -351 -350 CATCCCTAAAAACAGAGATAGATGCCACAATCGTGACTTACATTIGGAAG-3, $\quad-301$

IL-1 $\beta$ :

-250 5'-AAATAATGCCCATTTCCACCACGATGACACACTTGCGAATGTGTCACTAT -201

-200 CTGCCACCCCTTGACTTCCAGGGATTAGAAATTATTTCAGGGTAGCAATA -151

PPARE
-150 GCCTCTTCCCCTAAGAATTCCCATCAAGCTTCTCCCCCCTCCCCCACCCT-3,

IL-6:

-900 5'-AAGCCTCCTTGCATGACCTGGAAATGTTTTGGGGTGTCCTGGCAGCAGTG -851

-850 GGATCAGCACTAACAGATAAGGGCAACTCTCACAGAGACTAAAGGTCTIA -801


PPARE

MMP12:

-200 5'-AACTTTTCTCCACTGCAGAAAAATTGAAATGGGTAAAGAAGGGAAGAGTC -151 PPARE

-150 A CAACAAAGTGGACACAGTGAGGAGGCCCCCAGAATACCTCCCAAAGCAA -101

-100 CCCACTTCACCCACTTCCTCTTCCAAGACTCCCACTTCTTCATGCATTAA-3' -51

TNF- $\alpha$ :

-250 5'-CCCAGATTGCCACAGAATCCTGGTGGGGACGACGGGGAGGAGATTCCTTG -201 PPARE

-200 ATGCCTGGGTGTCCCCAACTTTCCAAACCCTCTGCCCCCGCGATGGAGAA -151

-150 GAAACCGAGACAGAGGTGTAGGGCCACTACCGCTTCCTCCACATGAGATC-3' -101 PPARE

\section{B}
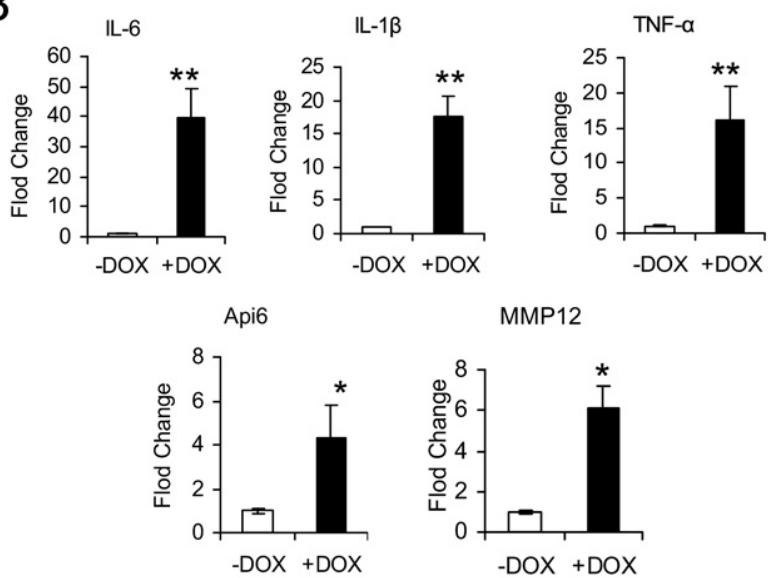

Figure 3. ChIP assay of dnPPAR $\gamma$-Flag fusion protein on the promoters of Api6, IL-1 $\beta$, IL-6, MMP12 and TNF- $\alpha$ inflammatory molecule genes in CCSPrtTA/(tetO) $)_{7}$-CMV-dnPPAR $\gamma$ bitransgenic mice. A: The amplified regions that contain putative PPAR $\gamma$ DNA binding sites (PPAR E) within the promoters of genes encoding Api $, I L-1 \beta, I L-6, M M P 12$, and $T N F-\alpha$. B: Statistical real-time PCR analyses of ChIP assay from dnPPAR $\gamma$-Flag fusion protein and promoters of Api $, I L-1 \beta, I L-6, M M P 12$, and TNF- $\alpha$ (mice, $n=4$ to 6). Relative binding levels were determined by $2^{(-\Delta \Delta \mathrm{Ct})}$, in which $\Delta \Delta \mathrm{C}_{\mathrm{t}}=\Delta \mathrm{C}_{\mathrm{t}(+\mathrm{DOX})}-$ $\Delta \mathrm{C}_{\mathrm{t}(-\mathrm{DOX})}$. The testing sample $\mathrm{C}_{\mathrm{t}}$ value was normalized by each input DNA fraction $\mathrm{C}_{\mathrm{t}}$ value, as $\Delta \mathrm{C}_{\mathrm{t}}=\mathrm{C}_{\mathrm{t}(\text { testing) }}-\left(\mathrm{C}_{\mathrm{t} \text { (input) }}-\log _{2 \text { (input dilution factor) }}\right)$. Data are reported as means $\pm \mathrm{SD} .{ }^{*} P<0.05 ;{ }^{* *} P<0.01$. - DOX, doxycyclineuntreated bitransgenic mice; +DOX, doxycycline-treated bitransgenic mice.

at the immature stage from differentiating into mature macrophages and neutrophils after dnPPAR $\gamma$ overexpression in AT II epithelial cells. This is similar to observations in $\mathrm{lal}^{-1-}$ mice. ${ }^{4}$

\section{Overexpression of dnPPAR $\gamma$ Suppresses $T$-Cell Proliferation in Bitransgenic Mice}

To assess T-cell proliferation, blood and lung mononuclear cells were isolated from 1-month, 4-month, and 8-month doxycycline-treated or untreated CCSP-rtTA/ (tetO) $)_{7}-\mathrm{CMV}$-dnPPAR $\gamma$ bitransgenic mice and stained with fluorochrome-conjugate anti-mouse CD3, CD4, and CD8 antibodies for FACS analysis. In contrast to myeloid cells, the percentage numbers of $\mathrm{CD}^{+}$cells in the blood and lung were significantly reduced in doxycyclinetreated CCSP-rtTA/(tetO) $)_{7}-\mathrm{CMV}$-dnPPAR $\gamma$ bitransgenic mice, compared with doxycycline-untreated controls (Figure 6, A and C). Similarly, the percentage numbers of $\mathrm{CD}^{+}$and $\mathrm{CD}^{+}$cells in the blood and lung were reduced in doxycycline-treated CCSP-rtTA/(tetO) $)_{7}-\mathrm{CMV}$ dnPPAR $\gamma$ bitransgenic mice (Figure 6, B and C). No change was observed in CCSP-rtTA single transgenic mice (see Supplemental Figure S1, F and G, at http://ajp. amjpathol.org). In these assays, the absolute numbers of $\mathrm{CD}^{+}, \mathrm{CD}^{+}$, and $\mathrm{CD}^{+}{ }^{+} \mathrm{T}$ cells were also reduced (Figure 6D). In some of the 1-month doxycyclinetreated samples, the differences of percentage numbers and absolute numbers between treated and untreated $\mathrm{CD}^{+}, \mathrm{CD}^{+}$, and $\mathrm{CD}^{+}{ }^{+}$cells showed no statistical significance. This is again similar to observations in $/\left.a\right|^{-1-}$ mice. ${ }^{4}$

\section{MDSCs Inhibit T-Cell Proliferation and Function}

In $/ a l^{-1-}$ mice, T-cell population reduction and functional impairment was due in part to MDSC suppression. ${ }^{4}$ To measure the effect of $\mathrm{CD} 11 \mathrm{~b}^{+} \mathrm{Gr}-1^{+}$cells on T-cell proliferation in CCSP-rtTA/(tetO) $7_{7}-\mathrm{CMV}-$ dnPPAR $\gamma$ bitransgenic mice, CFSE-labeled wild-type splenic CD4 ${ }^{+}$T cells were stimulated with anti-CD3 and anti-CD28 mAb in the



B
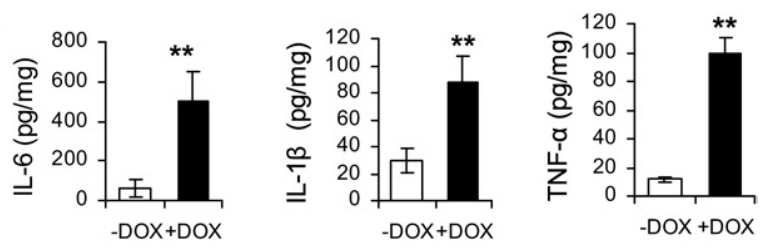

Figure 4. Overexpression of inflammatory cytokines in AT II epithelial cells and BALF of CCSP-rtTA/(tetO) $)_{7}$-CMV-dnPPAR $\gamma$ bitransgenic mice. A: Realtime PCR analysis of mRNA expression levels of inflammatory cytokines in AT II epithelial cells of CCSP-rtTA/(tetO) $)_{7}$-CMV-dnPPAR $\gamma$ bitransgenic mice that were treated or untreated with doxycycline for 2 months $(n=5)$. The mRNA expression level of GAPDH was used for normalization. Therefore, $\Delta \mathrm{C}_{\mathrm{t}}=\mathrm{C}_{\mathrm{t} \text { (testing) }}-\mathrm{C}_{\mathrm{t}(\mathrm{GAPDH})}$. Relative expression levels were determined by the $2^{-\Delta \Delta \mathrm{Ct}}$ method, in which $\Delta \Delta \mathrm{C}_{\mathrm{t}}=\Delta \mathrm{C}_{\mathrm{t}(+\mathrm{DOX})}-\Delta \mathrm{C}_{\mathrm{t}(-\mathrm{DOX})}$. Data are reported as means $\pm \mathrm{SD}$. ${ }^{*} P<0.05 ;{ }^{* *} P<0.01$. B: The protein expression levels of IL-1 $\beta$, IL- 6 , and TNF- $\alpha$ in BALF from the lungs of 4 -month doxycycline-treated or untreated CCSP-rtTA/(tetO) 7 -CMV-dnPPAR $\gamma$ bitransgenic mice by ELISA ( $n=5$ to 6 ). Data are reported as means \pm SD. ${ }^{* *} P<$ 0.01. - DOX, doxycycline-untreated bitransgenic mice; +DOX, doxycyclinetreated bitransgenic mice. 
A


GR-1
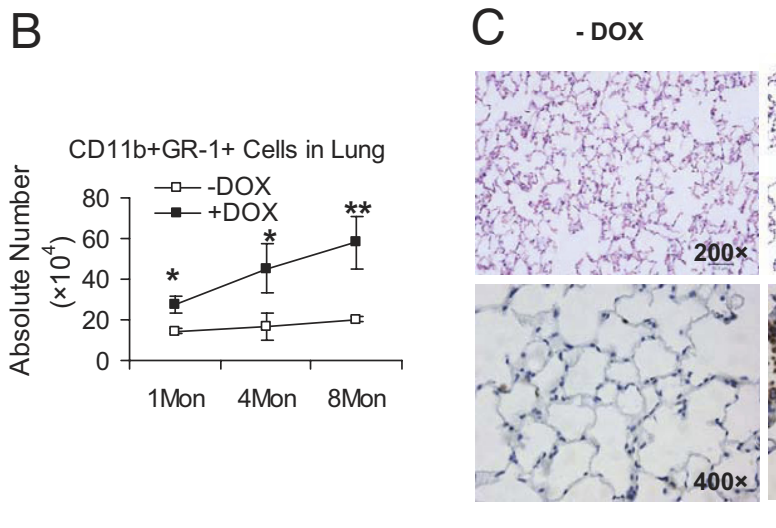

+DoX

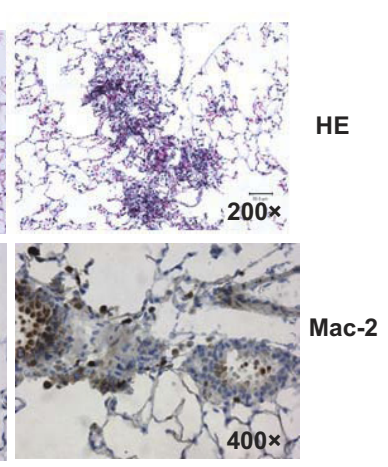

D

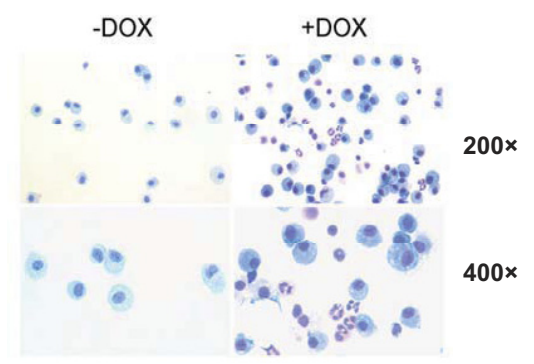

Figure 5. Myeloid cell populations in CCSPrtTA/(tetO) $)_{7}$-CMV-dnPPAR $\gamma$ bitransgenic mice Single-cell suspensions were prepared from the blood and lung of 1-month, 4-month, and 8-month doxycycline-treated and untreated CCSP-rtTA/ (tetO) $)_{7}$-CMV-dnPPAR $\gamma$ bitransgenic mice. A: The percentage number of $\mathrm{Gr}-1^{+} \mathrm{CD} 11 \mathrm{~b}^{+}$cell population was analyzed by FACS. A representative dotplot analysis of 4-month doxycycline-treated and untreated CCSP-rtTA/(tetO)-CMV-dnPPAR $\gamma$ bitransgenic mice is presented. Significant differences between doxycycline-treated and untreated groups at various time points were identified by two-way analysis of variance. Data are reported as means $\pm \mathrm{SD}(n=4$ to 6$) .{ }^{*} P<$ 0.05 . B: Absolute numbers of total $\mathrm{Gr}$ $1^{+} \mathrm{CD} 11 \mathrm{~b}^{+}$cells from the lungs of doxycyclinetreated and untreated CCSP-rtTA/(tetO) $)_{7}-\mathrm{CMV}$ dnPPAR $\gamma$ bitransgenic mice. Treatment duration 1 month, 4 months, or 8 months (1Mon, 4Mon, 8Mon). Significant differences between doxycycline-treated and untreated groups at various time points were identified by two-way analysis of variance. Data are reported as means \pm SD $(n=4$ to 6$) .{ }^{*} P<0.05 ;{ }^{* *} P<0.01$. C: H\&E staining (HE) and immunohistochemical staining with Mac 2 antibody (Mac-2) of lung tissue sections from representative 4-month doxycyclinetreated or untreated CCSP-rtTA/(tetO) $)_{7}$-CMVdnPPAR $\gamma$ bitransgenic mice with inflammatory cell infiltration. Original magnification as indicated on each image. D: Kwik-Diff staining of BALF cells from 11-month doxycycline-treated or untreated CCSP-rtTA/(tetO) $)_{7}$-CMV-dnPPAR $\gamma$ bitransgenic mice. -DOX, doxycycline-untreated bitransgenic mice; +DOX, doxycyclinetreated bitransgenic mice. Original magnification is indicated for each row. presence of CD11 $\mathrm{b}^{+} \mathrm{Gr}-1^{+}$cells that were isolated from the bone marrow, spleen, and lung of doxycyclinetreated or untreated mice. After 4 days coculturing, T-cell proliferation was measured by CFSE labeling dilution and flow cytometry. T cell receptor-stimulated T-cell proliferation (represented by multiple peaks) was suppressed by $\mathrm{CD} 11 \mathrm{~b}^{+} \mathrm{Gr}-1^{+}$cells from the lung of doxycyclinetreated bitransgenic mice, compared with $\mathrm{CD} 11 \mathrm{~b}^{+} \mathrm{Gr}-1^{+}$ cells of untreated bitransgenic mice (Figure 7A). In the PBS negative control group, no proliferation was observed. There was no change in $\mathrm{CD} 4^{+} \mathrm{T}$-cell proliferation in the CFSE labeling study under coculturing with MDSCs from the bone marrow or spleen, regardless of doxycycline treatment (data not shown). Thus, the defect caused by dnPPAR $\gamma$ overexpression in AT II epithelial cells was restricted to the lung.

A similar observation was made in the expression assay for the T-cell activation marker CD69. After 48 hours coculturing, CD11 $\mathrm{b}^{+} \mathrm{Gr}-1^{+}$cells from the lung of doxycycline-treated bitransgenic mice suppressed anti-CD3 Ab plus anti-CD28 Ab-stimulated CD69 expression, compared with $\mathrm{CD} 11 \mathrm{~b}^{+} \mathrm{Gr}-1^{+}$cells of untreated bitransgenic mice (Figure 7B). In this assay, CD11 $\mathrm{b}^{+} \mathrm{Gr}-1^{+}$cells from the bone marrow of doxycycline-treated bitransgenic mice showed slight suppression on CD69 expression, whereas $\mathrm{CD} 11 \mathrm{~b}^{+} \mathrm{Gr}-1^{+}$cells from the spleen of doxycycline-treated bitransgenic mice showed no suppression. In functional analysis, secretion of lymphokines was measured in MDSCS/CD4 T-cell coculturing medium by ELISA. CD $11 \mathrm{~b}^{+} \mathrm{Gr}-1^{+}$cells from the lungs of doxycycline-treated mice showed reduced secretion of $\mathrm{IL}-2$, IL-4, and IFN- $\gamma$ after T-cell receptor activation, compared with $\mathrm{CD} 11 \mathrm{~b}^{+} \mathrm{Gr}-1^{+}$cells of untreated bitransgenic mice (Figure 7C).

To determine whether $\mathrm{CD}^{+}{ }^{+} \mathrm{T}$-cell reduction is associated with apoptosis, CD4 ${ }^{+} \mathrm{T}$ cells were analyzed by annexin $\mathrm{V}$ staining. Only $\mathrm{CD} 4^{+} \mathrm{T}$ cells that were cocultured with $\mathrm{CD} 11 \mathrm{~b}^{+} \mathrm{Gr}-1^{+}$cells from the lungs of doxycyclinetreated bitransgenic mice showed increased apoptotic activity, compared with $\mathrm{CD} 11 \mathrm{~b}^{+} \mathrm{Gr}-1^{+}$cells of untreated bitransgenic mice (Figure 7D). Thus, dnPPAR $\gamma$-induced myeloid defect had a profound influence on T-cell proliferation and function. 
A

A B

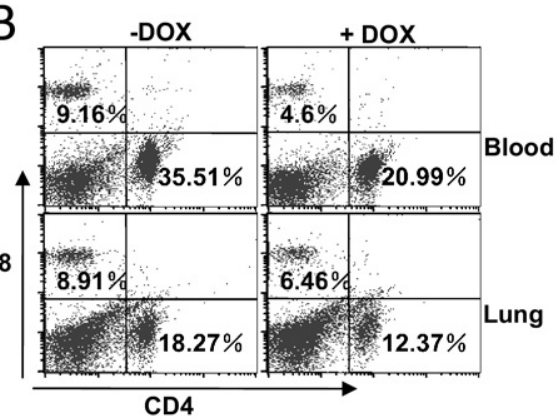

Figure 6. T-cell populations in CCSP-rtTA/ (tetO) ${ }_{7}-\mathrm{CMV}-\mathrm{dnPPAR} \gamma$ bitransgenic mice. Single-cell suspensions were prepared from the blood and lung of 1-month, 4-month, and 8-month (1Mon, 4Mon, 8Mon) doxycyclinetreated and untreated CCSP-rtTA/(tetO) $)_{7}$-CMVdnPPAR $\gamma$ bitransgenic mice. A: The percentage number of $\mathrm{CD}^{+}$cell population was analyzed by FACS. A representative histogram analysis of 4-month doxycycline-treated and untreated mice is presented. B: The percentage numbers of $\mathrm{CD}^{+}$, and $\mathrm{CD}^{+}$cell populations were analyzed by FACS. A representative dot-plot analysis of 4-month doxycycline-treated and untreated mice is presented. C: Percentage numbers of total $\mathrm{CD}^{+}, \mathrm{CD}^{+}$, and $\mathrm{CD}^{+}$cells from the blood and lungs of doxycycline-treated and untreated CCSP-rtTA/(tetO) $)_{7}$-CMV-dnPPAR $\gamma$ bitransgenic mice. Treatment duration: 1 month, 4 months, or 8 months (1Mon, 4Mon, 8 Mon). Significant differences between doxycycline-treated and untreated groups at various time points were identified by two-way analysis of variance. Data are reported as means \pm SD ( $n=4$ to 6 ). ${ }^{*} P<0.05$; ${ }^{* *} P<0.01$. D: Absolute numbers of total $\mathrm{CD}^{+}, \mathrm{CD}^{+}$, and $\mathrm{CD}^{+}$cells from the lungs of 1-month, 4-month, and 8-month (1Mon, 4Mon, 8Mon) doxycyclinetreated and untreated $\mathrm{CCSP}-\mathrm{rtTA} /\left(\operatorname{tetO}_{7}\right)_{-} \mathrm{CMV}$ dnPPAR $\gamma$ bitransgenic mice. Significant differences between doxycycline-treated and untreated groups at various time points were identified by two-way analysis of variance. Data are reported as means $\pm \mathrm{SD}(n=4$ to 6$)$. ${ }^{*} P<$ $0.05 ;{ }^{* *} P<0.01$. DOX, doxycycline-untreated bitransgenic mice; +DOX, doxycycline-treated bitransgenic mice

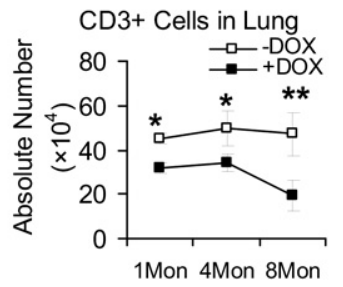

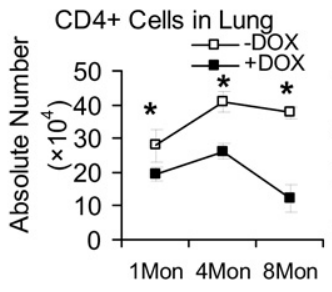

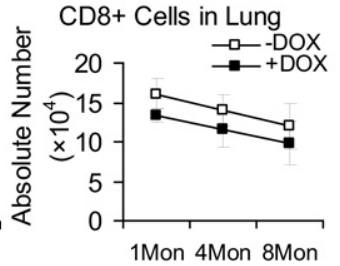

\section{Overexpression of dnPPAR $y$ Activates Intracellular Signaling Molecules in the Lung of Bitransgenic Mice}

In addition to immune response, nonimmune responses were investigated, such as intracellular signaling pathways that are activated by dnPPAR $\gamma$ overexpression in AT II epithelial cells. Single cells from the lung of 4-month doxycycline-treated or untreated CCSP-rtTA/(tetO) ${ }_{7-}$ CMV-dnPPAR $\gamma$ bitransgenic mice were costained with fluorochrome-conjugated SP-C antibody (AT II epithelial marker) and anti-phospho-Stat1, anti-phospho-Stat2, anti-phospho-Stat3, anti-phospho-Stat4, anti-phosphoStat5, anti-phospho-Stat6, anti-phospho-Erk1/2, or antiphospho-p38 antibody. Costained cells were analyzed by flow cytometry. Antibodies against these proteins were also included for total protein measurement by flow cytometry, for normalization. In the present study, AT II epithelial cells with activation of Stat1, Stat2, Stat3, Stat4, Erk1/2, and p38 and deactivation of Stat5 and Stat6 were observed in doxycycline-treated CCSP-rtTA/(tetO) $)_{7}$-CMV-dnPPAR $\gamma$ bitransgenic mice (Table 2). No change was observed in CCSP-
rtTA single transgenic mice (see Supplemental Table S1 at http://ajp.amjpathol.org). These results indicate that inactivation of the PPAR $\gamma$ pathway not only up-regulated proinflammatory cytokines but also activated a unique set of intracellular signaling molecules in AT II epithelial cells. When $\mathrm{CD} 11 \mathrm{~b}^{+} \mathrm{Gr}-1^{+}$MDSCs were analyzed, activation of Stat3, Erk1/2, and p38 was observed in doxycycline-treated CCSP-rtTA/(tetO) $)_{7}$-CMV-dnPPAR $\gamma$ bitransgenic mice, compared with untreated bitransgenic mice (Table 3).

It appears that inflammatory molecules induced by dnPPAR $y$ overexpression in the milieu of doxycyclinetreated CCSP-rtTA/(tetO) ${ }_{7}$-CMV-dnPPAR $\gamma$ bitransgenic lung activated oncogenic intracellular signaling molecules in AT II epithelial cells through the autocrine mechanism and those in $\mathrm{CD} 11 \mathrm{~b}^{+} \mathrm{Gr}-1^{+}$MDSCs through the paracrine mechanism.

\section{BMSC Conversion into AT II Epithelial Cells in the Lung of Bitransgenic Mice}

Bone marrow stem cells (BMSCs) are known to function in repair of injured AT II cells in emphysema. In our 


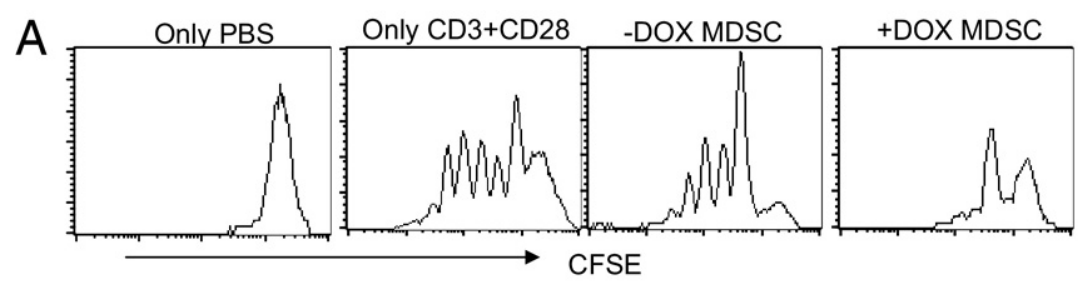



4 Mon
B

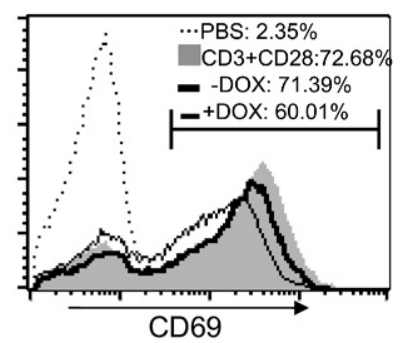

C

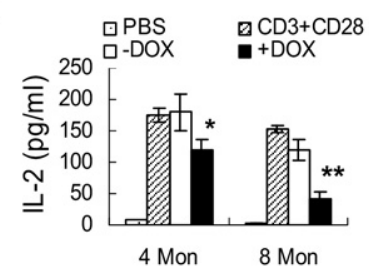

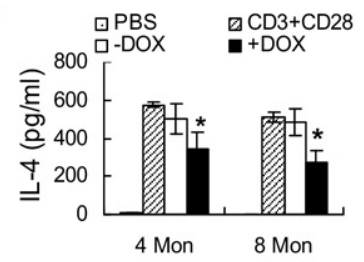

$0-$-Dox

+DOX

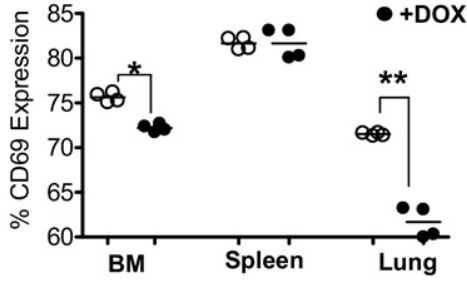

D

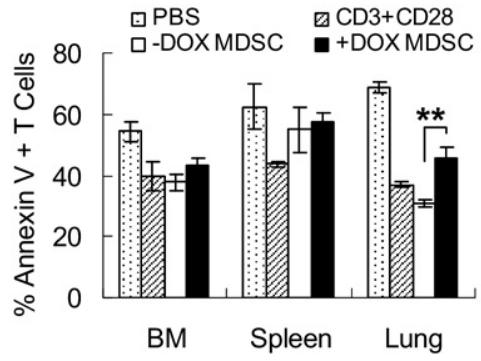

Figure 7. The suppressive function of MDSCs on $\mathrm{CD}^{+} \mathrm{T}$ cells. A: CFSE-labeled wild-type splenic $\mathrm{CD}_{4}{ }^{+} \mathrm{T}$ cells were stimulated with antiCD 3 and anti-CD28 $\mathrm{mAb}$ for 4 days in the presence or absence of $\mathrm{CD}_{11} \mathrm{~b}^{+} \mathrm{Gr}-1^{+}$MDSCs from the lung of doxycycline-treated or untreated CCSP-rtTA/(tetO) $)_{7}$-CMV-dnPPAR $\gamma$ bitransgenic mice. The ratio between MDSCs and splenic $\mathrm{CD}^{+}{ }^{+} \mathrm{T}$ cells was $1: 5$. Proliferation of labeled $\mathrm{CD}^{+}{ }^{+} \mathrm{T}$ cells was analyzed by flow cytometry. Peaks represent cell division cycles. PBS was negative control. B: Wild-type $\mathrm{CD}^{+} \mathrm{T}$ cells were stimulated with anti-CD3 and anti-CD28 $\mathrm{mAb}$ for 2 days in the presence or absence of $\mathrm{CD} 11 \mathrm{~b}^{+} \mathrm{Gr}-1^{+}$MDSCs from doxycycline-treated or untreated bitransgenic mice. Cells were stained with anti-CD4 and anti-CD69 antibodies for flow cytometry analysis. B, left: A representative study of lung MDSCs on CD69 expression. Dotted bar: PBS stimulation negative control. Shaded bar: anti-CD3 plus anti-CD28 mAb stimulation positive control. White bar: MDSCs from doxycycline-untreated bitransgenic mice Black bar: MDSCs from doxycycline-treated bitransgenic mice. B, right: Statistical analyses of CD69 expression by MDSCs from the bone marrow, spleen, and lung of doxycycline-treated or untreated bitransgenic mice. The percentage number of $\mathrm{CD} 69$ in $\mathrm{CD}^{+} \mathrm{T}$ cells is presented as mean $\pm \mathrm{SD}(n=4$ to 6$) .{ }^{*} P<0.05$; ${ }^{*} P<0.01$. C: The concentrations of IL- $2, \mathrm{IL}-4$, and IFN- $\gamma$ in the above cultured medium were measured by ELISA analysis. Significant differences between doxycycline-treated and untreated groups at various time points were identified by two-way analysis of variance. Data are reported as means $\pm \mathrm{SD}(n=4$ to 6). ${ }^{*} P<0.05$; ${ }^{* * *} P<0.01$. D: Prepared as described for panel $\mathbf{A}, \mathrm{CD}^{+}{ }^{+} \mathrm{T}$ cells were labeled with annexin $\mathrm{V}$ and $\mathrm{CD} 4$ antibodies for flow cytometry analysis. The percentage of annexin V-labeled $\mathrm{CD}^{+} \mathrm{T}$ cells is reported as means $\pm \mathrm{SD}$ (mice, $n=5) .{ }^{*} P<0.05$; ${ }^{* * *} P<0.01$. -DOX, doxycyclineuntreated bitransgenic mice; +DOX, doxycyclinetreated bitransgenic mice. previous study, LAL deficiency caused inflammation-induced BMSC conversion into AT II epithelial cells. ${ }^{17} \mathrm{Be}-$ cause PPAR $\gamma$ serves as a downstream effector of $L A L$, it is conceivable that BMSC-to-AT II cell conversion is regulated

Table 2. Phosphorylated Activation of Intracellular Signaling Molecules in Lung Alveolar Type II Epithelial Cells from CCSP-rtTA/(tetO) ${ }_{7}$-CMV-dnPPAR $\gamma$ Bitransgenic Mice

\begin{tabular}{lcclcl}
\hline & \multicolumn{2}{c}{ Percentage ratio (\%) } & & \multicolumn{2}{c}{ MFI ratio (\%) } \\
\cline { 2 - 3 } \cline { 5 - 6 } & - DOX & +DOX & & -DOX & \multicolumn{1}{c}{+ DOX } \\
\hline pStat1 & $10.37 \pm 3.18$ & $47.32 \pm 5.92^{* *}$ & & $22.42 \pm 9.18$ & $66.65 \pm 16.11^{* *}$ \\
pStat2 & $9.54 \pm 4.23$ & $33.47 \pm 6.12^{* *}$ & & $12.62 \pm 2.79$ & $27.78 \pm 5.45^{* *}$ \\
pStat3 & $6.47 \pm 2.1$ & $39.01 \pm 8.31^{* *}$ & & $11.22 \pm 3.13$ & $41.22 \pm 7.22^{* *}$ \\
pStat4 & $11.18 \pm 2.88$ & $42.11 \pm 4.35^{* *}$ & & $11.90 \pm 2.74$ & $14.72 \pm 3.85$ \\
pStat5 & $23.79 \pm 7.15$ & $9.50 \pm 4.69^{*}$ & & $30.09 \pm 10.65$ & $13.48 \pm 3.01^{*}$ \\
pStat6 & $25.81 \pm 6.8$ & $10.07 \pm 4.77^{*}$ & & $20.20 \pm 5.22$ & $18.48 \pm 4.52$ \\
pErk & $10.87 \pm 1.55$ & $33.78 \pm 3.33^{* *}$ & & $18.86 \pm 3.96$ & $51.30 \pm 7.76^{* *}$ \\
pP38 & $14.51 \pm 3.56$ & $41.11 \pm 10.49^{* *}$ & & $24.79 \pm 5.56$ & $59.05 \pm 9.55^{* *}$
\end{tabular}

-DOX, doxycycline-untreated bitransgenic mice; +DOX, doxycycline-treated bitransgenic mice.

Cells isolated from the lung were stained with anti-SP-C antibody, followed by intranuclear staining with anti-phospho-Stat1-6, anti-phospho-Erk, or anti-phospho-P38 antibody, and Stat1-6, Erk, or P38 antibody as described under Materials and Methods. Numbers of percentage ratio and mean fluorescent intensity (MFI) ratio between phospho-proteins and total proteins in gated SP-C positive cells from four independent experiments $(n=4)$ were calculated and statistically analyzed. ${ }^{*} P<0.05 ;{ }^{*} P<0.01$. by PPAR $\gamma$. To test this assumption, the purified adherent BMSCs from hSP-B 1.5-kb lacZ transgenic mice were injected into 2-month doxycycline-treated or untreated CCSPrtTA/(tetO) $)_{7}$-CMV-dnPPAR $\gamma$ recipient bitransgenic mice. AT II epithelial cells were isolated from recipient mice 2 months later and were double-stained with rabbit anti-proSP-C antibody (AT II cell marker) and mouse $\beta$-galactosidase anti-

Table 3. Phosphorylated Activation of Intracellular Signaling Molecules in Myeloid-Derived Suppressor Cells from CCSP-rtTA/(tetO) ${ }_{7}$-CMV-dnPPAR $\gamma$ Bitransgenic Mice

\begin{tabular}{lccccr}
\hline & \multicolumn{2}{c}{ Blood } & & \multicolumn{2}{c}{ Lung } \\
\cline { 2 - 3 } \cline { 5 - 6 } \cline { 5 - 6 } & -DOX & +DOX & & -DOX & +DOX \\
\hline pStat3 & $11.24 \pm 3.12$ & $39.78 \pm 6.31^{*}$ & & $16.87 \pm 4.15$ & $20.1 \pm 3.12$ \\
pErk & $13.58 \pm 4.88$ & $40.85 \pm 5.87^{*}$ & & $12.32 \pm 3.23$ & $33.55 \pm 4.45^{*}$ \\
pP38 & $15.46 \pm 4.37$ & $27.46 \pm 4.04^{*}$ & & $16.11 \pm 4.1$ & $27.05 \pm 2.13^{*}$ \\
\hline
\end{tabular}

-DOX, doxycycline-untreated bitransgenic mice; +DOX, doxycycline-treated bitransgenic mice.

Cells isolated from the blood and lung were stained with anti-CD11b and GR-1 antibodies, followed by intranuclear staining with anti-phosphoStat3, anti-phospho-Erk, or anti-phospho-P38 antibody, and Stat3, Erk, or P38 antibody as described under Materials and Methods. Numbers of percentage ratio between phospho-proteins and total proteins in gated CD11b and Gr-1 double positive cells from four independent experiments $(n=4)$ were calculated and statistically analyzed.

$$
{ }^{*} P<0.05 \text {. }
$$




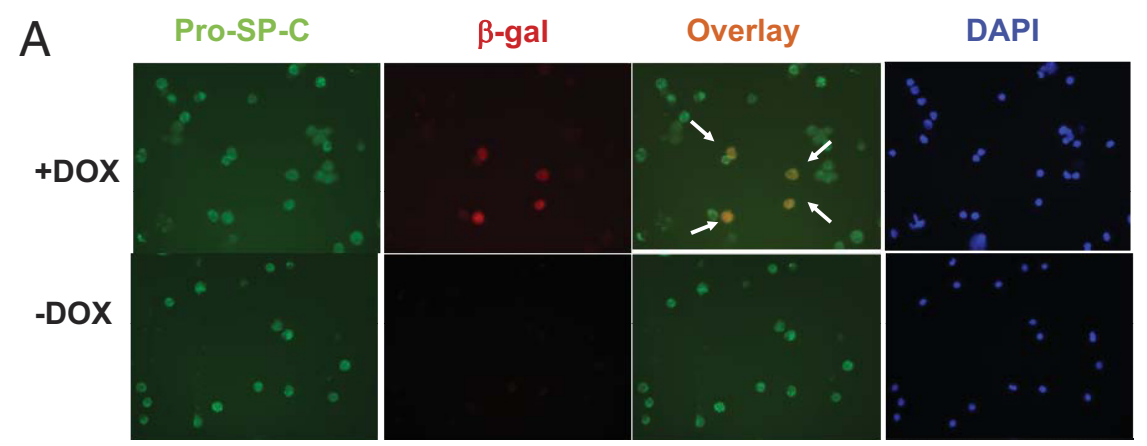

B

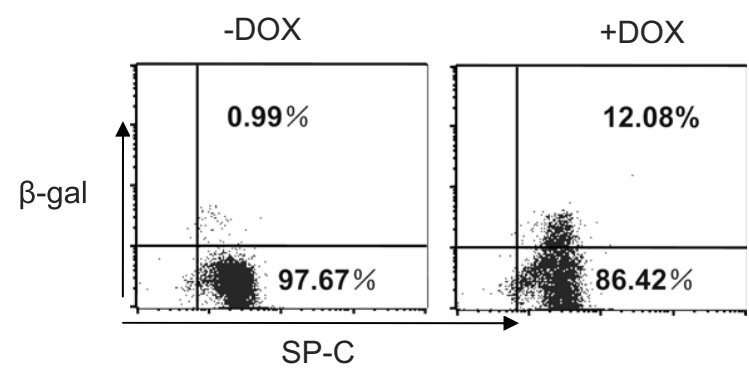

body (Figure 8A). Compared with doxycycline-untreated bitransgenic mice, treated bitransgenic mice showed approximately $10 \%$ double-positive AT II epithelial cells. To further quantify the conversion rate of hSP-B 1.5-kb lacZ adherent BMSCs, the purified AT II epithelial cells from the lung of recipient mice (double-stained with proSP-C antibody and $\beta$-galactosidase antibody) were analyzed by flow cytometry (Figure 8B). In this method, approximately $12 \%$ AT II epithelial cells showed $\beta$-galactosidase and proSP-C double-positive in doxycycline-treated mice, compared with untreated mice.

\section{Discussion}

We have previously reported that blockage of PPAR $\gamma$ ligand synthesis during LAL deficiency caused exuberant inflammation and emphysema in the lung,${ }^{1}$ implicating PPAR $\gamma$ inactivation as responsible for these phenotypes. To identify the pathophysiological roles of PPAR $\gamma$ in the lung, a doxycycline-controlled CCSP-rtTA/(tetO) $7_{7}^{-}$ CMV-dnPPAR $\gamma$ bitransgenic mouse model was generated to overexpress dnPPAR $\gamma$ in lung epithelial cells (Figure $1 \mathrm{~A}$ ) and so block the function of endogenous PPAR $\gamma$. In this bitransgenic model, doxycycline treatment induced dnPPAR $\gamma$-Flag fusion protein expression in AT ॥ epithelial cells at both mRNA and protein levels (Figure 1, B-D). Flow cytometry analysis showed dnPPAR $\gamma$-Flag fusion protein expression associated with AT II epithelial cells (Figure 1D). This is consistent with our previous observation, in which the same CCSP-rtTA system dictated expression of Stat3C-Flag fusion protein and MMP12-Flag fusion protein in AT II epithelial cells. ${ }^{11,14}$ As a consequence, emphysema was developed in the bitransgenic lung. This is in agreement with a previous finding. ${ }^{23}$ To elucidate the relationship between inflammation and dnPPAR $\gamma$-induced emphysema, various pro-
Figure 8. BMSCs conversion into AT II epithelial cells in the lung of CCSP-rtTA/(tetO) $)_{7}-\mathrm{CMV}$ dnPPAR $\gamma$ bitransgenic mice. A: Double-immunofluorescence staining of prosP-C and $\beta$ -galactosidase in purified AT II epithelial cells from CCSP-rtTA/(tetO) $)_{7}$-CMV-dnPPAR $\gamma$ bitransgenic mice that were injected with hSP-B 1.5-kb lacZ BMSCs. Arrows point to colocalized proSP-C and $\beta$-galactosidase positive AT II epithelial cells. DAPI represents nuclear staining. B: FACS analysis of AT II epithelial cells from the lungs of recipient CCSP-rtTA/(tetO) $)_{7}-\mathrm{CMV}$ dnPPAR $\gamma$ bitransgenic mice after hSP-B $1.5-\mathrm{kb}$ lacZ BMSC injection. The cells were double-labeled with anti-SP-C and $\beta$-galactosidase antibodies. Data are reported as means \pm SD $(n=$ 6). ${ }^{* *} P<0.01$. DOX, doxycycline-untreated bitransgenic mice; +DOX, doxycycline-treated bitransgenic mice. inflammatory cytokines were investigated. The rationale for this is based on two facts: emphysema is a chronic inflammatory disease and PPAR $\gamma$ is an anti-inflammation transcription factor after ligand binding.

In doxycycline-treated CCSP-rtTA/(tetO) $)_{7}-\mathrm{CMV}$-dnPPAR $\gamma$ bitransgenic mice, overexpression of dnPPAR $\gamma$ significantly increased concentrations of IL- $1 \beta, \mathrm{IL}-6$, and TNF- $\alpha$ in BALF at an early time point ( $<2$ months of doxycycline treatment) (Figure 4B). Real-time PCR analysis revealed that at least AT II epithelial cells were the source cells for synthesis of these and other proinflammatory molecules, after suppression of the endogenous PPAR $\gamma$ anti-inflammatory function (Figure 4A). ChIP assay indicated that augment of these molecules was due to directly DNA binding of dnPPAR $\gamma$ on the promoters of these genes (Figure 3). Up-regulation of IL-6 and IL-13 has been reported to cause emphysema in the lung. ${ }^{24,25}$ Severity of elastaseinduced emphysema was decreased in IL-1 $\beta$ and TNF- $\alpha$ receptor-deficient mice. ${ }^{26}$

dnPPAR $\gamma$ can induce proinflammatory gene expression by two mechanisms at the transcriptional level. First, PPAR $\gamma$ suppresses gene expression by antagonizing the activities of AP-1, Stat1, Stat3, and NF $\kappa$ B through physical interaction. ${ }^{9,27,28}$ It is conceivable that overexpression of dnPPAR $\gamma$ interferes with the PPAR $\gamma$ antagonizing function on these factors to promote proinflammatory gene expression. Alternatively, dnPPAR $\gamma$ may suppress the endogenous PPAR $\gamma$ function by defectiveness of ligand-dependent coactivator recruitment and ligand-dependent release of corepressor. ${ }^{19}$ For example, the nuclear receptor-interacting MED/TRAP220 subunit of the coactivator complex is required for PPAR $\gamma$ function. ${ }^{29,30}$

Up-regulation of these proinflammatory cytokines subsequently triggered accumulation of MDSCs in the lung and circulation system 4 months after doxycycline treatment (Figure 5). $\mathrm{IL}-1 \beta$ is capable of inducing $\mathrm{CD} 11 \mathrm{~b}^{+} \mathrm{Gr}-1^{+}$ 
MDSC accumulation in mice. ${ }^{31,32}$ IL-6 can partially restore the accumulation of $\mathrm{CD} 11 \mathrm{~b}^{+} \mathrm{Gr}-1^{+} \mathrm{MDSC}$ in IL-1 receptor (IL-1R)-deficient mice. ${ }^{33}$ In CD $11 b^{+} \mathrm{Gr}-1^{+}$MDSCs from dnPPAR $\gamma$ overexpressed bitransgenic mice, multiple intracellular signaling molecules were overactivated (Table 3). It is known that MDSCs suppress T-cell proliferation and function to subvert immune surveillance and prevent the immune system from eliminating unwanted pathogenic events. ${ }^{21,22,34}$ Indeed, decreased numbers of $\mathrm{CD}^{+}, \mathrm{CD}^{+}$, and $\mathrm{CD}^{+} \mathrm{T}$ cells were observed in doxycycline-treated CCSP-rtTA/(tetO) $)_{7}-\mathrm{CMV}$-dnPPAR $\gamma$ bitransgenic lungs in correlation with $\mathrm{CD} 11 \mathrm{~b}^{+} \mathrm{Gr}-1^{+}$MDSCs expansion 4 months after doxycycline treatment (Figure 6). This observation was further supported by the in vitro coculturing study, in which CD11 b ${ }^{+} \mathrm{Gr}-1^{+}$MDSCs isolated from dnPPAR $\gamma$ overexpressing bitransgenic mice significantly reduced proliferation, lymphokine production, and CD69 expression of wild-type $\mathrm{CD} 4^{+} \mathrm{T}$ cells that were stimulated by anti-CD3 mAb plus anti-CD28 mAb (Figure 7).

This observation is consistent with clinical studies in which $\mathrm{CD}^{+}$and $\mathrm{CD} 8^{+} \mathrm{T}$ cells were significantly reduced in the peripheral blood and BALF of patients with chronic obstructive pulmonary disease (COPD). ${ }^{35,36}$ The severity of COPD is directly correlated with decreased numbers of $\mathrm{CD}^{+}$and $\mathrm{CD}^{+} \mathrm{T}$ cells in peripheral blood mononuclear cells. ${ }^{37,38}$ Although MDSC-induced T-cell immunosuppression was initially reported in cancer, the present study demonstrates a link between MDSC and emphysema, a major phenotype in COPD. COPD and lung cancer are major diseases associated with smoking in humans. Because MDSCs are heterogenous populations, it remains to be determined which MDSC subpopulations induce tumor and which subpopulations induce emphysema.

In AT II epithelial cells, a set of intracellular signaling molecules that include Stat1, Stat2, Stat3, Stat4, Erk1/2, and p38 showed increased phosphorylation (activation) by dnPPAR $\gamma$ overexpression (Table 2). This can be a result of up-regulation of proinflammatory cytokine stimuli through autocrine pathways. Activation of these pathways can further exacerbate inflammation and pathogenic phenotypes by stimulating proinflammatory downstream genes. This is supported by clinical observations. For example, up-regulation of Stat3 and its downstream genes served as biomarkers for COPD diagnosis in humans. ${ }^{39}$ Activation of STAT-4 and Erk in the lung tissue was observed in emphysema patients, compared with lungs of control subjects. ${ }^{40,41}$

One important group of PPAR $\gamma$ negatively regulated genes in the lung is the MMPs., ${ }^{1,2}$ MMP up-regulation facilitates degradation of extracellular matrix to weaken the interstitial alveolar structure, resulting in pulmonary emphysema. ${ }^{20}$ For example, gene ablation of MMP12 conferred resistance to emphysema. ${ }^{42}$ Likewise, overexpression of MMP12 caused emphysema and lung cancer. ${ }^{11}$ MMP12 gene regulation can be directly inhibited by PPAR $\gamma$ in lung epithelial cells and is down-regulated in PPAR $\gamma$ ligand-treated $l a l^{-1-}$ mice. $^{2}$ After dnPPAR $\gamma$ overexpression, the mRNA levels of MMP12, along with MMP2, MMP7, MMP8, and MMP9, were all up-regulated in AT II epithelial cells from doxycycline-treated CCSPrtTA/(tetO) $)_{7}-\mathrm{CMV}$-dnPPAR $\gamma$ bitransgenic mice (Figure
2D). As a result, the enzymatic activities of MMP9 and MMP12 were increased in BALF of doxycycline-treated CCSP-rtTA/(tetO) $)_{7}-\mathrm{CMV}$-dnPPAR $\gamma$ bitransgenic mice that contributed to emphysema formation (Figure 2D).

Emphysema can trigger infiltration of BMSCs into the lung to repair injured AT II cells. ${ }^{43}$ It would therefore be intriguing to see whether dnPPAR $\gamma$-induced emphysema causes BMSC infiltration into the lung to convert into AT II cells. We have previously reported that inactivation of the endogenous PPAR $\gamma$ function by blocking ligand synthesis promoted BMSCs to convert into AT II epithelial cells in lal $^{-1-}$ mice as part of pathogenesis. ${ }^{17}$ Based on the observations of double-immunofluorescence staining and FACS analysis in the present study, BMSCs from hSP-B 1.5-kb lacZ donor mice showed the ability to convert into AT II epithelial cells during pulmonary inflammation and injury in the doxycycline-treated CCSP-rtTA/ (tetO) $)_{7}-\mathrm{CMV}$-dnPPAR $\gamma$ bitransgenic lung (Figure 8A). Conversion did not occur in doxycycline-untreated bitransgenic mice. Although it is generally thought that BMSCs can regenerate injured AT II epithelial cells during lung injury, for regenerative medicine one concern is that BMSCs may contribute to emphysema and cancer development, because BMSCs possess T-cell immune suppressive function similar to that exhibited by MDSCs. ${ }^{44,45}$

In summary, overexpression of dnPPAR $\gamma$ relieved endogenous PPAR $\gamma$ suppression of the transcriptional activities of proinflammatory genes, including cytokines and MMPs. This action promoted inflammatory cell infiltration (especially MDSCs) into the lung and changed the regional microenvironment. In the nonimmune response, AT II epithelial cells were changed, as evident from activation of multiple intracellular signaling molecules. As a consequence, emphysema was formed. The action also promoted conversion of BMSCs into AT II epithelial cells during injury. Infiltration of MDSCs and BMSCs reduced T-cell proliferation and function in the lung. These observations support the concept that the LAL/ligands/PPAR $\gamma$ axis plays a critical role in maintaining alveolar homeostasis by suppressing pulmonary inflammation.

\section{Acknowledgments}

We thank Dr. Xuemei Lian, Ph.D. (Cincinnati Children's Hospital Medical Center, Cincinnati, $\mathrm{OH})$, for assistance with Kwik-Diff staining and Miss Beilin Li (Indiana University and Perdue University) for animal genotyping.

\section{References}

1. Lian $X$, Yan C, Yang L, Xu Y, Du H: Lysosomal acid lipase deficiency causes respiratory inflammation and destruction in the lung. Am J Physiol Lung Cell Mol Physiol 2004, 286:L801-L807

2. Lian X, Yan C, Qin Y, Knox L, Li T, Du H: Neutral lipids and peroxisome proliferator-activated receptor-\{gamma\} control pulmonary gene expression and inflammation-triggered pathogenesis in lysosomal acid lipase knockout mice. Am J Pathol 2005, 167:813-821

3. Yan C, Lian X, Li Y, Dai Y, White A, Qin Y, Li H, Hume DA, Du H: Macrophage-specific expression of human lysosomal acid lipase corrects inflammation and pathogenic phenotypes in lal-/- mice. Am J Pathol 2006, 169:916-926 
4. Qu P, Shelley WC, Yoder MC, Wu L, Du H, Yan C: Critical roles of lysosomal acid lipase in myelopoiesis. Am J Pathol 2010, 176:2394-2404

5. Qu P, Du H, Wilkes DS, Yan C: Critical roles of lysosomal acid lipase in T cell development and function. Am J Pathol 2009, 174:944-956

6. Li AC, Brown KK, Silvestre MJ, Willson TM, Palinski W, Glass CK: Peroxisome proliferator-activated receptor gamma ligands inhibit development of atherosclerosis in LDL receptor-deficient mice. J Clin Invest 2000, 106:523-531

7. Marx N, Kehrle B, Kohlhammer K, Grüb M, Koenig W, Hombach V, Libby P, Plutzky J: PPAR activators as antiinflammatory mediators in human T lymphocytes. Implications for atherosclerosis and transplantation-associated arteriosclerosis. Circ Res 2002, 90:703-710

8. Jiang C, Ting AT, Seed B: PPAR-gamma agonists inhibit production of monocyte inflammatory cytokines. Nature 1998, 391:82-86

9. Wang LH, Yang XY, Zhang X, Huang J, Hou J, Li J, Xiong H, Mihalic $\mathrm{K}, \mathrm{Zhu} \mathrm{H}$, Xiao W, Farrar WL: Transcriptional inactivation of STAT3 by PPARgamma suppresses IL-6-responsive multiple myeloma cells. Immunity 2004, 20:205-218

10. Qu P, Du H, Li Y, Yan C: Myeloid-specific expression of Api6/AIM/Sp alpha induces systemic inflammation and adenocarcinoma in the lung. J Immunol 2009, 182:1648-1659

11. Qu P, Du H, Wang X, Yan C: Matrix metalloproteinase 12 overexpression in lung epithelial cells plays a key role in emphysema to lung bronchioalveolar adenocarcinoma transition. Cancer Res 2009, 69: 7252-7261

12. Yang L, Yan D, Yan C, Du H: Peroxisome proliferator-activated receptor gamma and ligands inhibit surfactant protein B gene expression in the lung. J Biol Chem 2003, 278:36841-36847

13. Tichelaar JW, Lu W, Whitsett JA: Conditional expression of fibroblast growth factor-7 in the developing and mature lung. J Biol Chem 2000, 275:11858-11864

14. Li Y, Du H, Qin Y, Roberts J, Cummings OW, Yan C: Activation of the signal transducers and activators of the transcription 3 pathway in alveolar epithelial cells induces inflammation and adenocarcinomas in mouse lung. Cancer Res 2007, 67:8494-8503

15. Rice WR, Conkright JJ, Na CL, Ikegami M, Shannon JM, Weaver TE: Maintenance of the mouse type II cell phenotype in vitro. Am J Physiol Lung Cell Mol Physiol 2002, 283:L256-L264

16. Yan C, Naltner A, Conkright J, Ghaffari M: Protein-protein interaction of retinoic acid receptor alpha and thyroid transcription factor- 1 in respiratory epithelial cells. J Biol Chem 2001, 276:21686-21691

17. Yan C, Lian X, Dai Y, Wang X, Qu P, White A, Qin Y, Du H: Gene delivery by the hSP-B promoter to lung alveolar type II epithelial cells in LAL-knockout mice through bone marrow mesenchymal stem cells. Gene Ther 2007, 14:1461-1470

18. Yang L, Naltner A, Kreiner A, Yan D, Cowen A, Du H, Yan C: An enhancer region determines hSP-B gene expression in bronchiolar and ATII epithelial cells in transgenic mice. Am J Physiol Lung Cell Mol Physiol 2003, 284:L481-L488

19. Gurnell M, Wentworth JM, Agostini M, Adams M, Collingwood TN, Provenzano C, Browne PO, Rajanayagam O, Burris TP, Schwabe JW, Lazar MA, Chatterjee VK: A dominant-negative peroxisome proliferator-activated receptor gamma (PPARgamma) mutant is a constitutive repressor and inhibits PPARgamma-mediated adipogenesis. J Biol Chem 2000, 275:5754-5759

20. Shapiro SD, Senior RM: Matrix metalloproteinases. Matrix degradation and more. Am J Respir Cell Mol Biol 1999, 20:1100-1102

21. Ostrand-Rosenberg S, Sinha P: Myeloid-derived suppressor cells: linking inflammation and cancer. J Immunol 2009, 182:4499-4506

22. Gabrilovich DI, Nagaraj S: Myeloid-derived suppressor cells as regulators of the immune system. Nat Rev Immunol 2009, 9:162-174

23. Simon DM, Arikan MC, Srisuma S, Bhattacharya S, Tsai LW, Ingenito EP, Gonzalez F, Shapiro SD, Mariani TJ: Epithelial cell PPARy contributes to normal lung maturation. FASEB J 2006, 20:1507-1509

24. Kuhn C 3rd, Homer RJ, Zhu Z, Ward N, Flavell RA, Geba GP, Elias JA: Airway hyperresponsiveness and airway obstruction in transgenic mice. Morphologic correlates in mice overexpressing interleukin (IL)-11 and IL-6 in the lung. Am J Respir Cell Mol Biol 2000, 22:289-295

25. Hoshino T, Kato S, Oka N, Imaoka H, Kinoshita T, Takei S, Kitasato Y, Kawayama T, Imaizumi T, Yamada K, Young HA, Aizawa H: Pulmonary inflammation and emphysema: role of the cytokines IL-18 and IL-13. Am J Respir Crit Care Med 2007, 176:49-62

26. Lucey EC, Keane J, Kuang PP, Snider GL, Goldstein RH: Severity of elastase-induced emphysema is decreased in tumor necrosis factor- alpha and interleukin-1beta receptor-deficient mice. Lab Invest 2002, 82:79-85

27. Ricote M, Li AC, Willson TM, Kelly CJ, Glass CK: The peroxisome proliferator-activated receptor-gamma is a negative regulator of macrophage activation. Nature 1998, 391:79-82

28. Castrillo A, Mojena M, Hortelano S, Bosca L: Peroxisome proliferatoractivated receptor-gamma-independent inhibition of macrophage activation by the non-thiazolidinedione agonist L-796,449. Comparison with the effects of 15-deoxy-delta(12,14)-prostaglandin $\mathrm{J}(2)$. J Biol Chem 2001, 276:34082-34088

29. Ge K, Cho YW, Guo H, Hong TB, Guermah M, Ito M, Yu H, Kalkum M, Roeder RG: Alternative mechanisms by which mediator subunit MED1/TRAP220 regulates peroxisome proliferator-activated receptor gamma-stimulated adipogenesis and target gene expression. Mol Cell Biol 2008, 28:1081-1091

30. Ge K, Guermah M, Yuan CX, Ito M, Wallberg AE, Spiegelman BM, Roeder RG: Transcription coactivator TRAP220 is required for PPAR gamma 2-stimulated adipogenesis. Nature 2002, 417:563-567

31. Bunt SK, Sinha P, Clements VK, Leips J, Ostrand-Rosenberg S: Inflammation induces myeloid-derived suppressor cells that facilitate tumor progression. J Immunol 2006, 176:284-290

32. Tu S, Bhagat G, Cui G, Takaishi S, Kurt-Jones EA, Rickman B, Betz KS, Penz-Oesterreicher M, Bjorkdahl O, Fox JG, Wang TC: Overexpression of interleukin-1beta induces gastric inflammation and cancer and mobilizes myeloid-derived suppressor cells in mice. Cancer Cell 2008, 14:408-419

33. Bunt SK, Yang L, Sinha P, Clements VK, Leips J, Ostrand-Rosenberg $\mathrm{S}$ : Reduced inflammation in the tumor microenvironment delays the accumulation of myeloid-derived suppressor cells and limits tumor progression. Cancer Res 2007, 67:10019-10026

34. Sica A, Bronte V: Altered macrophage differentiation and immune dysfunction in tumor development. J Clin Invest 2007, 117:1155-1166

35. Barcelo B, Pons J, Fuster A, Sauleda J, Noguera A, Ferrer JM, Agusti AG: Intracellular cytokine profile of $T$ lymphocytes in patients with chronic obstructive pulmonary disease. Clin Exp Immunol 2006, 145 474-479

36. Gupta J, Chattopadhaya D, Bhadoria DP, Qadar Pasha MA, Gupta VK, Kumar M, Dabur R, Yadav V, Sharma GL: T Iymphocyte subset profile and serum alpha-1-antitrypsin in pathogenesis of chronic obstructive pulmonary disease. Clin Exp Immunol 2007, 149:463-469

37. Di Stefano A, Capelli A, Lusuardi M, Caramori G, Balbo P, Ioli F, Sacco S, Gnemmi I, Brun P, Adcock IM, Balbi B, Barnes PJ, Chung $\mathrm{KF}$, Donner CF: Decreased T lymphocyte infiltration in bronchial biopsies of subjects with severe chronic obstructive pulmonary disease. Clin Exp Allergy 2001, 31:893-902

38. Zhu X, Gadgil AS, Givelber R, George MP, Stoner MW, Sciurba FC, Duncan SR: Peripheral T cell functions correlate with the severity of chronic obstructive pulmonary disease. J Immunol 2009, 182:32703277

39. Qu P, Roberts J, Li Y, Albrecht M, Cummings OW, Eble JN, Du H, Yan C: Stat3 downstream genes serve as biomarkers in human lung carcinomas and chronic obstructive pulmonary disease. Lung Cancer 2009, 63:341-347

40. Di Stefano A, Caramori G, Capelli A, Gnemmi I, Ricciardolo FL, Oates T, Donner CF, Chung KF, Barnes PJ, Adcock IM: STAT4 activation in smokers and patients with chronic obstructive pulmonary disease. Eur Respir J 2004, 24:78-85

41. Mercer BA, Kolesnikova N, Sonett J, D'Armiento J: Extracellular regulated kinase/mitogen activated protein kinase is up-regulated in pulmonary emphysema and mediates matrix metalloproteinase- 1 induction by cigarette smoke. J Biol Chem 2004, 279:17690-17696

42. Hautamaki RD, Kobayashi DK, Senior RM, Shapiro SD: Requirement for macrophage elastase for cigarette smoke-induced emphysema in mice. Science 1997, 277:2002-2004

43. Weiss DJ, Kolls JK, Ortiz LA, Panoskaltsis-Mortari A, Prockop DJ: Stem cells and cell therapies in lung biology and lung diseases. Proc Am Thorac Soc 2008, 5:637-667

44. Alison MR, Lim S, Houghton JM: Bone marrow-derived cells and epithelial tumours: more than just an inflammatory relationship. Curr Opin Oncol 2009, 21:77-82

45. Djouad F, Plence P, Bony C, Tropel P, Apparailly F, Sany J, Noël D, Jorgensen C: Immunosuppressive effect of mesenchymal stem cells favors tumor growth in allogeneic animals. Blood 2003, 102:3837-3844 